\title{
A generalized simulation capability for rotating- beam scatterometers
}

\author{
Zhen Li, Ad Stoffelen, and Anton Verhoef \\ R\&D Satellite Observation, Royal Netherlands Meteorological Institute, de Bilt, 3731 GA, the Netherlands
}

Correspondence: Zhen Li (li@knmi.nl)

Received: 12 July 2018 - Discussion started: 30 November 2018

Revised: 12 June 2019 - Accepted: 13 June 2019 - Published: 4 July 2019

\begin{abstract}
Rotating-beam wind scatterometers exist in two types: rotating fan-beam and rotating pencil-beam. In our study, a generic simulation frame is established and verified to assess the wind retrieval skill of the three different scatterometers: SCAT on CFOSAT (China France Oceanography SATellite), WindRad (Chinese Wind Radar) on FY-3E, and SeaWinds on QuikSCAT. Besides the comparison of the so-called first rank solution retrieval skill of the input wind field, other figures of merit (FoMs) are applied to statistically characterize the associated wind retrieval performance from three aspects: wind vector root mean square error, ambiguity susceptibility, and wind biases. The evaluation shows that, overall, the wind retrieval quality of the three instruments can be ranked from high to low as WindRad, SCAT, and SeaWinds, where the wind retrieval quality strongly depends on the wind vector cell (WVC) location across the swath. Usually, the higher the number of views, the better the wind retrieval, but the effect of increasing the number of views reaches saturation, considering the fact that the wind retrieval quality at the nadir and sweet swath parts stays relatively similar for SCAT and WindRad. On the other hand, the wind retrieval performance in the outer swath of WindRad is improved substantially as compared to SCAT due to the increased number of views. The results may be generally explained by the different incidence angle ranges of SCAT and WindRad, mainly affecting azimuth diversity around nadir and number of views in the outer swath. This simulation frame can be used for optimizing the Bayesian wind retrieval algorithm, in particular to avoid biases around nadir but also to investigate resolution and accuracy through incorporating and analyzing the spatial response functions of the simulated Level-1B data for each WVC.
\end{abstract}

\section{Introduction}

The wind scatterometer has been proven to be a powerful instrument for global sea surface wind measurement. The wind retrievals have a wide variety of applications, including nowcasting and assimilation in numerical weather prediction models, as well as oceanography, climate research, and offshore energy applications (Offiler, 1984; Naderi et al., 1991; Stoffelen and Anderson, 1997; Portabella, 2002; Bajo et al., 2017). The wind retrieval is achieved by inverting a set of radar cross-section measurements $\left(\sigma^{\circ}\right)$ at different geometries (incidence and/or azimuth look angles) over a wind vector cell (WVC) through a geophysical model function (GMF) to extract the wind. The more diversity in the geometry, the better wind retrieval will be achieved (Portabella, 2002).

Currently, there are two types of scatterometer in orbit: multiple fixed fan-beam and rotating pencil-beam instruments. The first wind scatterometer in space was the SEASAT-A Scatterometer System (SASS) on SEASAT-A launched in June 1978 by NASA with four fixed fan beams and dual co-polarization (VV and $\mathrm{HH}) \mathrm{Ku}$-band $(13.2 \mathrm{GHz}$ ) emitting and receiving antennas, which failed in October 1978 (Offiler, 1984). The term "views" in this paper means measurements of the surface $\sigma^{0}$ at different azimuth angle and/or incidence angle and/or polarizations, and each surface $\sigma^{0}$ measurement is aggregated from the samples with the same polarization and similar azimuth and incidence angle. The geometric diversity of the views is able to improve the wind retrieval accuracy. "Views" is different from the term "looks" in radar, which is defined as the equivalent number of independent samples in a particular $\sigma^{0}$ measurement and specifies the measurement variance (Ulaby and Long, 2013). This scatterometer had two views only per wind vector cell (WVC), a VV view and an HH view, which turned 
out to be insufficient to resolve the wind direction unambiguously well. The ERS-1 and ERS-2 satellites carried a scatterometer on board as of 1991 three fixed fan beams and vertical co-polarization ( VV) at C-band frequency $(5.4 \mathrm{GHz})$, with all beams pointing to the right-hand side of the satellite. After ERS-1 and ERS-2, the NASA Scatterometer (NSCAT) was launched in 1996 on the Japanese Advanced Earth Observing Satellite (ADEOS-I). It had six fan beams with VV capability on the fore and after beams and both VV and horizontal (HH) co-polarization on the mid beams (Naderi et al., 1991). The European Space Agency (ESA) developed the Advanced Scatterometer (ASCAT) on the Metop satellite series, which has six C-band VV fan beams, three of each pointing to the left and right of the swath, and it started to provide data in 2006 (Gelsthorpe et al., 2000). The ERS-1 and ERS-2, NSCAT, and ASCAT instruments all use three independent views per WVC, leading to a reduced wind direction ambiguity as compared to SASS, by sampling the main second harmonic wind direction dependency of the geophysical model function (GMF) well (Stoffelen and Anderson, 1997; Stoffelen and Portabella, 2006). SeaWinds, the first rotating pencil-beam scatterometer, was developed by NASA and launched on QuikSCAT (1999), on the Japanese satellite ADEOS-2 (2003), and flew as RapidScat on the International Space Station in 2014. It has two Ku-band rotating pencil beams measuring VV and $\mathrm{HH}$, respectively, at two fixed incidence angles (Hoffman and Leidner, 2005). All current and prior rotating pencil-beam scatterometers are similar in design concept to SeaWinds and differ primarily in the incidence angles used. The OSCAT scatterometer on OceanSat-2 is a $\mathrm{Ku}$-band rotating pencil-beam instrument similar to SeaWinds and developed by the Indian Space Research Organization (ISRO). It was launched in 2009 and failed in 2014 (Singh et al., 2012). After that, ISRO launched SCATSat-1 in 2016 as an OceanSat-2 replacement mission with the same scatterometer design, and OceanSat-3 will be launched in 2020. China launched its first $\mathrm{Ku}$-band rotating pencil-beam scatterometer on board HY-2A in 2011, and it is still currently in operation (Jiang et al., 2012). SeaWinds-class rotating pencil-beam scatterometers are able to obtain four independent views per WVC in the inner swath but only two independent views per WVC in the outer swath, where only vertically polarized views are available. This will impose similar ambiguity problems as in the SASS design.

A new type of scatterometer - the Rotating Fan-beam SCATterometer (RFSCAT) - in the $\mathrm{Ku}$ band was proposed in 2000 (Lin et al., 2000b). It combines the features from fixed fan-beam and rotating pencil-beam scatterometers, which provide large swath coverage and increase the diversity in the observation geometry. The scatterometer (referred to as SCAT from now on) on board CFOSAT (China France Oceanography SATellite) and WindRad (Chinese Wind Radar on FY-3E) belong to this type of scatterometer, and CFOSAT was launched on 29 October 2018, while WindRad is planned to be launched in 2019 (Dou et al.,
2014). These represent a rotating fan-beam instrument with $\mathrm{Ku}$ band only (SCAT), a rotating fan-beam instrument with both $\mathrm{Ku}$ and $\mathrm{C}$ band (WindRad), and a rotating pencil-beam instrument with $\mathrm{Ku}$ band only (SeaWinds).

The aim of our study is to build a generic simulation system and construct an evaluation frame, particularly fit for the above rotating-beam scatterometers, including $\mathrm{Ku}$-band and C-band types. The simulation system includes the complete simulation of satellite orbital movement, Level-1B (L1B) data generation, Level-2A (L2A) data generation, and Level2B (L2B) wind retrieval. The three different rotating-beam scatterometers are expected to perform differently, due to their varying observation geometry and nonlinear wind retrieval characteristics, e.g., wind direction ambiguity. The wind retrieval results are carefully evaluated and compared. The advantages and disadvantages are analyzed such that they can be used as a design reference.

\section{Simulation method}

\subsection{CFOSAT, WindRad, and SeaWinds characteristics}

The RFSCAT characteristics have been studied and assessed by Lin et al. (2000a, 2002). The slowly rotating fan beam sweeps over the swath and the different views overlap in each WVC, which leads to multiple views in a given WVC (Fig. 1). Contrary to the fixed fan-beam and rotating pencilbeam instruments, the number of views in a WVC depends on its location and varies across the swath as a function of the rotating speed. The scanning geometry results in a smaller number of views and less azimuth diversity in the outer and the nadir parts of the swath, which lead to a degraded wind retrieval performance. In contrast, the other region of the swath (named the sweet swath) has a better wind retrieval performance than the outer and nadir swath.

SCAT and WindRad are both rotating fan-beam designs, but they have somewhat different characteristics. They both follow the RFSCAT principles, but SCAT has two fan beams operating in the $\mathrm{Ku}$ band with $\mathrm{VV}$ and $\mathrm{HH}$ respectively, whereas WindRad has four fan beams. Two of these beams are operating in the $\mathrm{Ku}$ band at $\mathrm{VV}$ and $\mathrm{HH}$ respectively, while the other two are operating at $\mathrm{VV}$ and $\mathrm{HH}$ in the $\mathrm{C}$ band. All the antennas transmit and receive pulses in turns (see the illustrations in Fig. 1). The main parameters for simulating SCAT and WindRad are listed in Tables 1 and 2.

Rotating pencil-beam scatterometers have been flying on board several satellites as described in the Introduction. SeaWinds is taken as representative for the rotating pencil-beam design in our study. It has one dish antenna of about $1 \mathrm{~m}$ diameter with a VV and $\mathrm{HH}$ beam conically scanning at a speed of $18 \mathrm{rpm}$, which is much faster than the rotating fan beam (Fig. 2). The VV beam has a higher incidence angle than the $\mathrm{HH}$ beam, resulting in a wider VV swath. There are four integrated views produced at all WVCs, for those lo- 


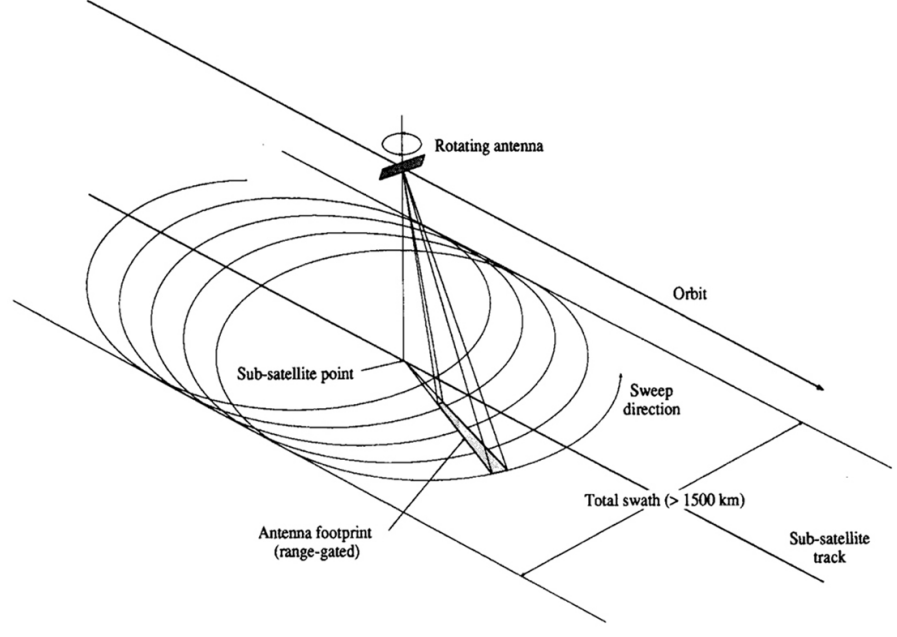

(a)

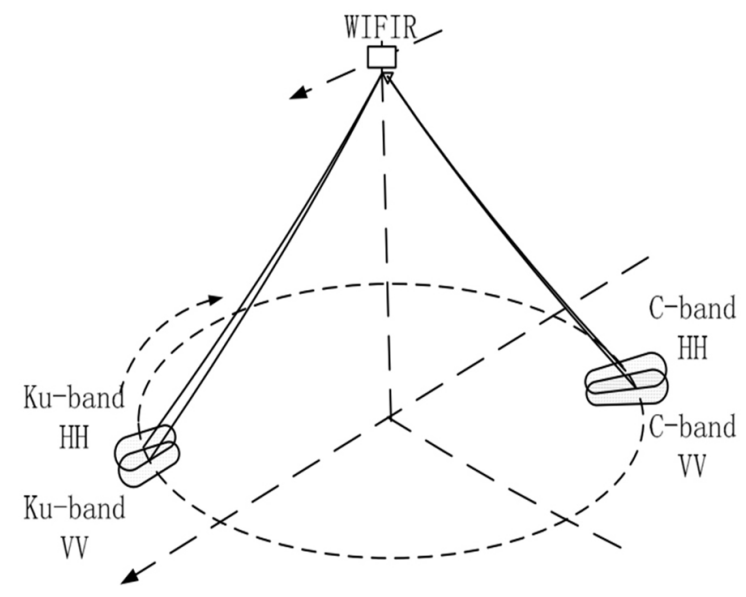

(b)

Figure 1. Rotating fan-beam scatterometer. (a) SCAT (Lin et al., 2000a). (b) WindRad (Dou et al., 2014).

Table 1. Main parameters of CFOSAT SCAT.

\begin{tabular}{ll}
\hline Parameters & Value \\
\hline Orbit height & $514 \mathrm{~km}$ \\
Swath & $1000 \mathrm{~km}$ \\
Footprint & $280 \mathrm{~km}$ \\
Satellite speed & $7.1 \mathrm{~km} \mathrm{~s}-1$ \\
Antenna rotating speed & $3.5 \mathrm{rpm}$ \\
Polarization & VV and HH al- \\
& ternating \\
Incidence angle range & $25-48^{\circ}$ \\
Antenna pointing angle & $40^{\circ}$ \\
Peak transmit power & $120 \mathrm{~W}$ \\
WVC resolution & $25 \mathrm{~km}$ \\
Center frequency & $13.256 \mathrm{GHz}$ \\
& $(\mathrm{Ku} \mathrm{band})$ \\
Duration of transmit pulse & $1.3 \mathrm{~ms}$ \\
Duration of receiving pulse & $2.7 \mathrm{~ms}$ \\
Pulse repetition frequency (PRF) & $75 \mathrm{~Hz}$ \\
Two-way -3 dB beam width (azimuth) & $1.28^{\circ}$ \\
Peak antenna gain & $30 \mathrm{~dB}$ \\
Transmit bandwidth & $0.5 \mathrm{MHz}$ \\
&
\end{tabular}

cated in the inner swath by segregating both VV and $\mathrm{HH}$ and fore and aft views. The four views in the outer swath that are used in the retrieval are all VV views, also divided into fore and aft views but each split in two azimuth groups. The main parameters of the SeaWinds instrument are listed in Table 3.

NESZ (noise equivalent sigma-zero) is a range of values depending on the specific slice position within the antenna footprint on the ground. Figures 3, 4, and 5 give the NESZ

Table 2. Main parameters of FY-3E WindRad.

\begin{tabular}{|c|c|c|}
\hline \multirow[t]{2}{*}{ Parameters } & \multicolumn{2}{|c|}{ Value } \\
\hline & $\mathrm{Ku}$ band & $\mathrm{C}$ band \\
\hline Orbit height & \multicolumn{2}{|c|}{$836 \mathrm{~km}$} \\
\hline Swath & \multicolumn{2}{|c|}{$1400 \mathrm{~km}$} \\
\hline Footprint & \multicolumn{2}{|c|}{$200 \mathrm{~km}$} \\
\hline Satellite speed & \multicolumn{2}{|c|}{$7.4 \mathrm{~km} \mathrm{~s}^{-1}$} \\
\hline Antenna rotating speed & \multicolumn{2}{|c|}{$3.0 \mathrm{rpm}$} \\
\hline Polarization & \multicolumn{2}{|c|}{$\mathrm{VV}$ and $\mathrm{HH}$ alternating } \\
\hline Incidence angle range & \multicolumn{2}{|c|}{$34.7-44.5^{\circ}$} \\
\hline Antenna pointing angle & \multicolumn{2}{|c|}{$34.8^{\circ}$} \\
\hline WVC resolution & \multicolumn{2}{|c|}{$25 \mathrm{~km}$} \\
\hline Peak transmit power & $120 \mathrm{~W}$ & $100 \mathrm{~W}$ \\
\hline Center frequency & $13.256 \mathrm{GHz}$ & $5.4 \mathrm{GHz}$ \\
\hline $\begin{array}{l}\text { Duration of transmit } \\
\text { pulse }\end{array}$ & $1.8 \mathrm{~ms}$ & $1.7 \mathrm{~ms}$ \\
\hline $\begin{array}{l}\text { Duration of receiving } \\
\text { pulse }\end{array}$ & $1.25 \mathrm{~ms}$ & $1 \mathrm{~ms}$ \\
\hline $\begin{array}{l}\text { Pulse repetition } \\
\text { frequency (PRF) }\end{array}$ & $208 \mathrm{~Hz}$ & $104 \mathrm{~Hz}$ \\
\hline $\begin{array}{l}\text { Two-way }-3 \mathrm{~dB} \\
\text { azimuth beam width }\end{array}$ & $1.3^{\circ}$ & $0.52^{\circ}$ \\
\hline Peak antenna gain & $37 \mathrm{~dB}$ & $32 \mathrm{~dB}$ \\
\hline Transmit bandwidth & \multicolumn{2}{|c|}{$0.6 \mathrm{MHz}$} \\
\hline
\end{tabular}




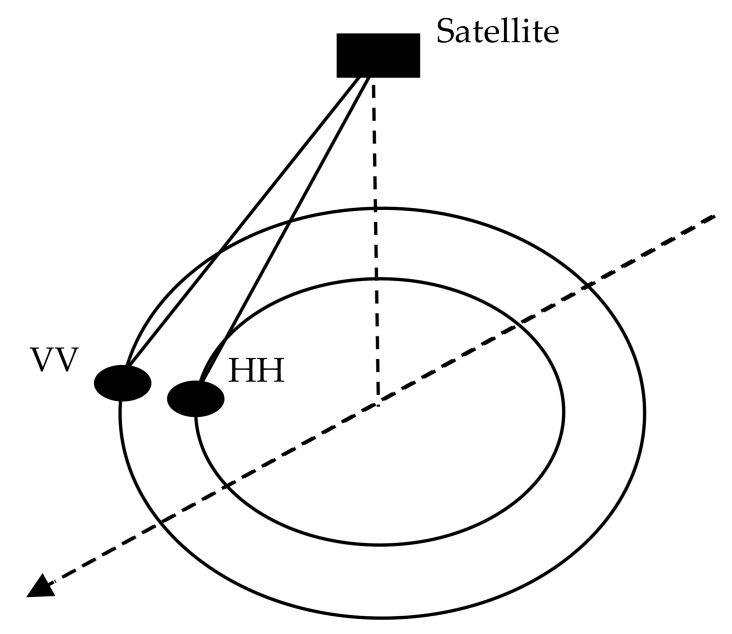

Figure 2. Rotating pencil-beam scatterometer.

Table 3. Main parameters of QuikSCAT SeaWinds.

\begin{tabular}{ll}
\hline Parameters & $\begin{array}{l}\text { Value (inner } \\
\text { and } \\
\text { outer beam) }\end{array}$ \\
& $800 \mathrm{~km}$ \\
\hline Orbit height & $1800 \mathrm{~km}$ \\
Swath & $36 \mathrm{~km}$ \\
Footprint & $7.0 \mathrm{~km} \mathrm{~s}-1$ \\
Satellite speed & $18 \mathrm{rpm}$ \\
Antenna rotating speed & VV and HH \\
Polarization & 51.8 and $46.7^{\circ}$ \\
Incidence angle range & 44.9 and $38.9^{\circ}$ \\
Antenna pointing angle & $120 \mathrm{~W}$ \\
Peak transmit power & $25 / 12.5 \mathrm{~km}$ \\
WVC resolution & $13.256 \mathrm{GHz}$ \\
Center frequency & $(\mathrm{Ku} \mathrm{band})$ \\
& $1.5 \mathrm{~ms}$ \\
Duration of transmit pulse & $2.1 \mathrm{~ms}$ \\
Duration of receiving pulse & $96 \mathrm{~Hz}$ \\
Pulse Repetition Frequency (PRF) & $1.8^{\circ}$ \\
Two-way - 3 dB beam width (azimuth) & $38 \mathrm{~dB}$ \\
Peak antenna gain & $0.375 \mathrm{MHz}$ \\
Transmit bandwidth &
\end{tabular}

distribution as a function of the slice number for SCAT, WindRad, and SeaWinds.

\subsection{Simulation procedure}

The simulation is designed to be generic and able to adapt to all of the current rotating-beam wind scatterometers, i.e., both pencil-beam and fan-beam types. It consists of four components: (1) generate satellite state vectors by the orbit propagator SGP4 (Simplified perturbation models) (Hoots and Roehrich, 1980); (2) simulate L1B data; (3) assign the L1B data onto the proper WVCs; (4) aggregate L1B data in one WVC into views (L2A data). The work flowcharts are shown in Figs. 6 and 7. We use ECMWF model wind as the input wind field to initialize the L1B simulation, which provides a spatially smooth ocean wind truth. In order to simplify the simulation procedure, the pulse is cut into equalsize slices. To represent the sampling of local wind variability (turbulence), geophysical noise is added by disturbing the input wind components $u$ and $v$ assigned on each slice by injecting Gaussian distributed noise. Together with the instrument configurations and satellite state vectors, the observation geometries on slice level are calculated. The instrument noise $\mathrm{Kpc}$ (Long et al., 2004) is estimated by $\mathrm{Kpc}^{2}=A+\frac{B}{\mathrm{SNR}}+\frac{C}{\mathrm{SNR}^{2}}$. However, the coefficients $A, B$, and $C$ need onboard processing details, which are not the same nor available for all scatterometers. In order to make the simulator generic, $A, B$, and $C$ for each slice are calculated by $A=\frac{1}{B_{\mathrm{s}} \times t_{\mathrm{d}}}, B=\frac{2}{B_{\mathrm{s}} \times t_{\mathrm{r}}}$, and $C=\frac{1}{B_{\mathrm{s}} \times t_{\mathrm{r}}}$, where $B_{\mathrm{s}}$ is the bandwidth for each individual slice, $t_{\mathrm{d}}$ is the transmit duration time, and $t_{\mathrm{r}}$ is the receiving time. The distribution of $B_{\mathrm{S}}$ on each slice in one pulse is assigned according to the antenna gain pattern of the pulse.

An example of the simulated satellite orbit together with the location of the slices is given in Fig. $8 . \sigma^{\circ}$ is derived using the NSCAT-4 GMF for the Ku band and the CMOD5n GMF for the $\mathrm{C}$ band and the corresponding beam geometries. Subsequently, the L1B data are obtained after adding the instrument noise on the "true" $\sigma^{\circ}$. The instrument noise is added by multiplying a Gaussian random number in this way: $\sigma_{\text {noise }}^{o}=\sigma^{0} \times(1+\mathrm{Kpc} \times$ Gaussian_random_nr $)$. The L1B data are assigned to the proper WVCs (Dunbar et al., 2001) and then aggregated into views. A view is a group of slices with similar azimuth angle and the same polarization in one WVC; the properties (i.e., incidence angle, azimuth angle, latitude, longitude, etc.) on the corresponding slices are also aggregated to represent the view ( $\mathrm{Li}$ et al., 2017). We note that the simulation does currently not include rain effect.

\subsection{Wind field retrieval principle}

Maximum likelihood estimation (MLE) is the most classic algorithm for wind retrieval. It has been applied in many wind retrieval studies (Chi and Li, 1988; JPL, 2001; Pierson, 1989; Portabella and Stoffelen, 2002). We adopted it and applied it in our wind retrievals. The MLE can be expressed as (JPL, 2001)

MLE $=\frac{1}{N} \sum_{i=1}^{N}\left(\frac{\sigma_{\mathrm{m} i}^{\mathrm{o}}-\sigma_{\mathrm{s} i}^{\mathrm{o}}}{\operatorname{Kp}\left(\sigma_{\mathrm{x} i}^{\mathrm{o}}\right)}\right)^{2}$,

where $N$ is the number of views, and $\sigma_{\mathrm{x} i}^{\mathrm{o}}$ is either $\sigma_{\mathrm{m} i}^{\mathrm{o}}$ (measured $\sigma^{\circ}$ ) or $\sigma_{\mathrm{s} i}^{\mathrm{o}}$ (trial simulated $\sigma^{\mathrm{o}}$ ). $\mathrm{Kp}\left(\sigma_{\mathrm{x} i}^{\mathrm{o}}\right)$ is the expected Gaussian observation noise with the form of $\mathrm{Kp} \times \sigma_{\mathrm{x} i}^{\mathrm{o}}$. The wind inversion procedure takes L2A data and searches for the $\sigma_{\mathrm{s} i}^{\mathrm{o}}$ with minimum MLE by varying trial wind speeds and directions. The $\sigma_{\mathrm{s} i}^{\mathrm{o}}$ with the minimum MLE is known 


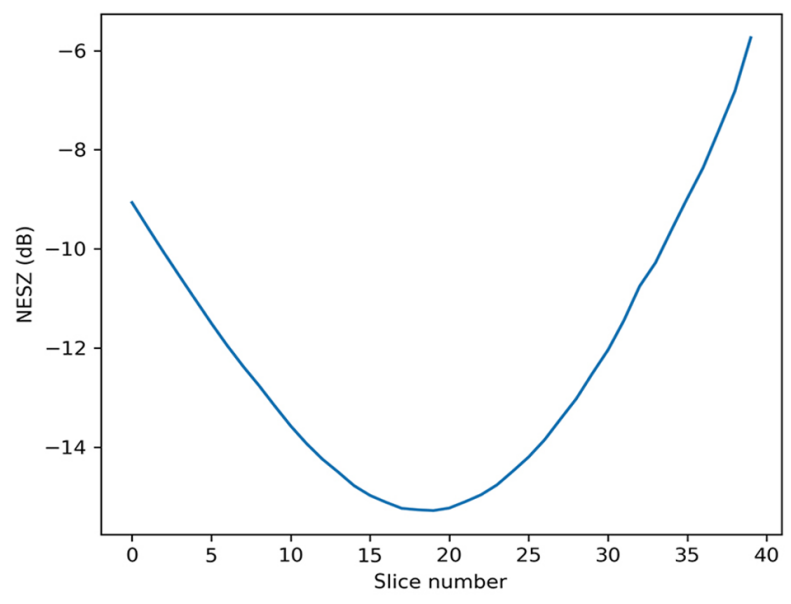

(a)

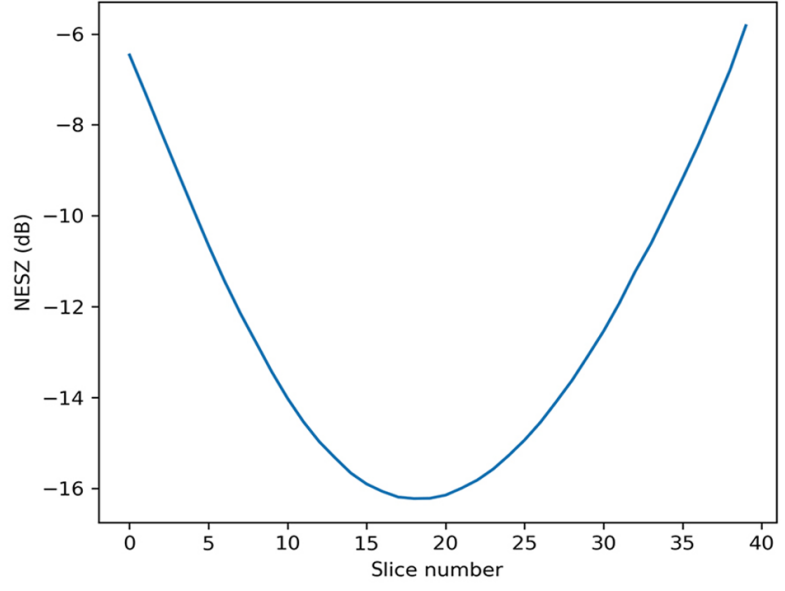

(b)

Figure 3. SCAT NESZ distribution as a function of slice number. (a) Ku-band HH polarization. (b) Ku-band VV polarization.

as the first rank solution. However, the first solution is often not the best solution because the wind retrieval results usually consist of a set of ambiguous solutions due to the combination of measurement geometry, the harmonic modulation of the GMF (nonlinear GMF), and noise, etc. After the wind retrieval step, one of the ambiguous solutions is selected by the two-dimensional variational ambiguity removal (2DVAR) (Vogelzang, 2013) after minimizing a total cost function that combines both observational and NWP background contributions. The retrieved wind field can be compared with the input wind field to assess the wind retrieval quality.

\subsection{Simulation assessment}

\subsubsection{Simulation model validation}

The performance of the scatterometer simulator on actual wind field is a good means to establish the validity of the simulation model. SeaWinds is chosen to compare real data with simulated data because it is the only scatterometer for which real data are available among the three scatterometers here. In total 14 orbits (one day) of data are included in the validation. The maximum collocation distance between real and simulated data points is set to $10 \mathrm{~km}$, and the number of collocated data is 75867 ; Fig. 9 shows the collocated wind retrieval result. The simulated wind speed and wind direction give a good correlation with the real SeaWinds data, which means the simulation model has a good performance as compared to the real scatterometer, and it is suitable for the comparison among the different types of scatterometers.

\subsubsection{SCAT, WindRad, and SeaWinds view number comparison}

The most important differences between SCAT, WindRad, and SeaWinds are the shape of the antenna and the number of antennas, directly leading to a different distribution of the number of views across the swath. SeaWinds, as a rotating pencil-beam instrument, has four views in each WVC across the swath, where the fore and aft views in the outer swath are each split in two views. The number of slices in each view varies across the swath though. For rotating fan-beam instruments, the view number varies across the swath, with the feature of fewer views in the outer and nadir swath and more views in the parts of the swath in between (Fig. 10). It can be observed that both SCAT and WindRad contain more views than SeaWinds for all WVCs, with a saddle shape in the view count. Moreover, the number of views of WindRad is about twice the number of views of SCAT.

\subsubsection{Instrument noise}

The instrument noise (Kpc) of the simulator for SCAT, Win$\mathrm{dRad}$, and SeaWinds is estimated at various wind speeds (4, 9 , and $16 \mathrm{~m} \mathrm{~s}^{-1}$ ) on slice level and WVC level. The Kpc for each view is aggregated by weighting the Kpc of the slices in this view, and the Kpc on WVC level is derived by averaging the Kpc for all the views in the corresponding WVC.

Figure 11a shows the slice Kpc of SCAT as a function of incidence angle. The slices with low wind speed and high incidence angle contain high $\mathrm{Kpc}$, and $\mathrm{Kpc}$ for $\mathrm{VV}$ polarization overall is lower than for $\mathrm{HH}$, except for the slices with incidence angle lower than $30.25^{\circ}$ (indicated by the dashed line in Fig. 11a). The Kpc in a WVC for SCAT (Fig. 11b) is much lower than the Kpc on slice level, as expected due to the aggregation of the slices in a WVC. The outer swath contains 


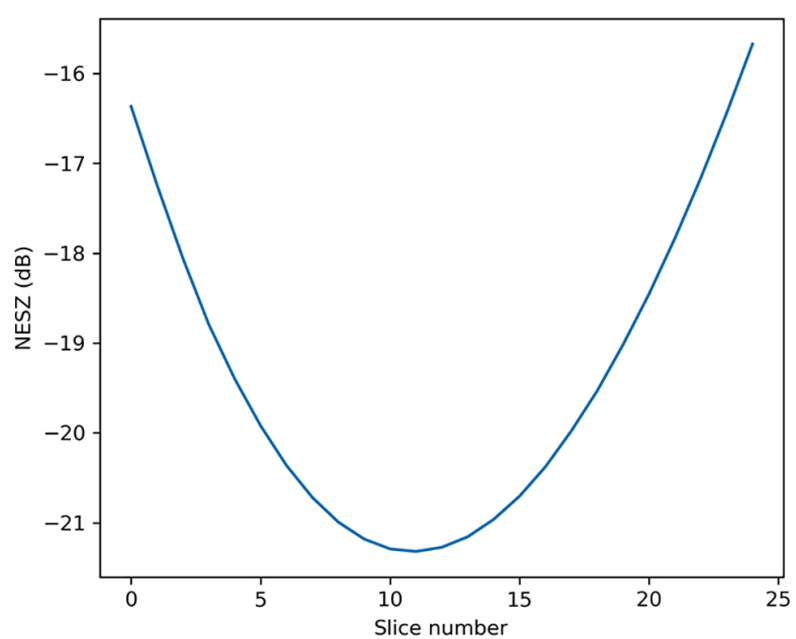

(a)

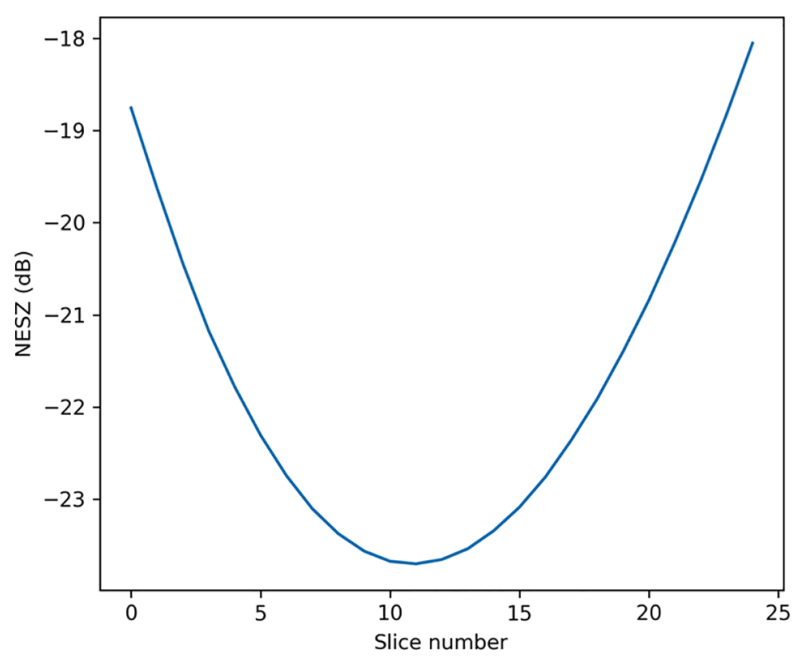

(c)

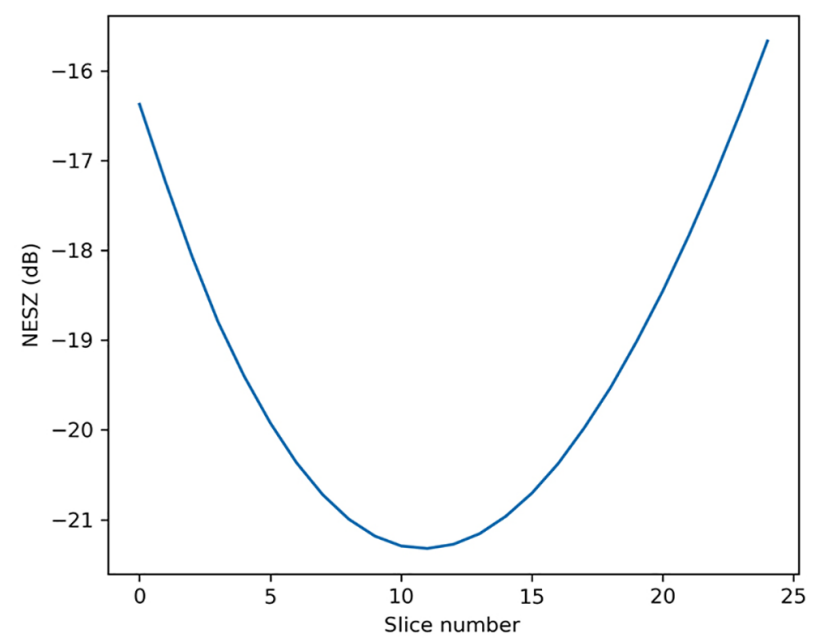

(b)

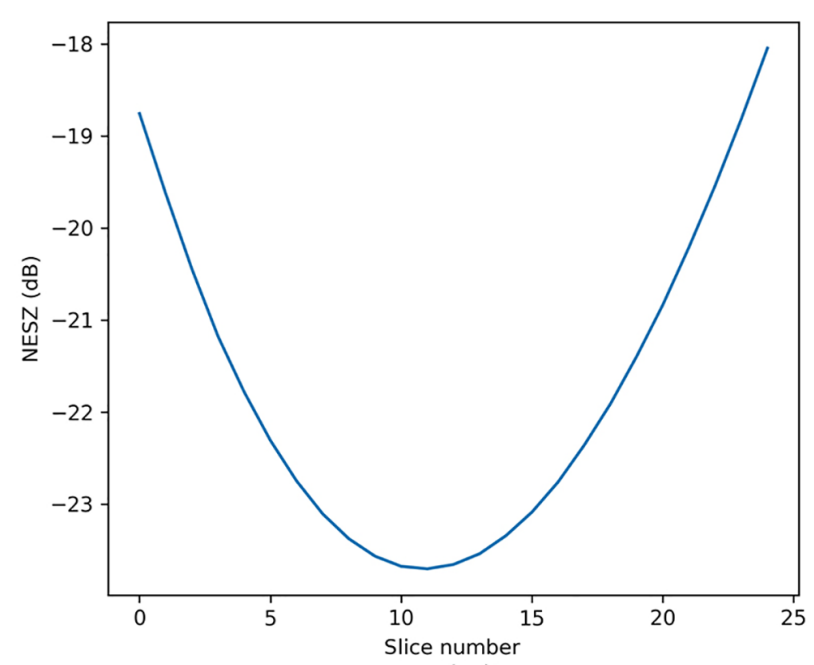

(d)

Figure 4. WindRad NESZ distribution as a function of slice number. (a) Ku-band HH polarization. (b) Ku-band VV polarization. (c) C-band HH polarization. (d) C-band VV polarization.

relatively high instrument noise as compared to sweet and nadir swath. Low wind speed leads to a higher Kpc. On the WVC level, the instrument noise is lower than $20 \%$ except for low wind speed.

WindRad has two frequencies at the $\mathrm{Ku}$ and $\mathrm{C}$ band. As illustrated in Fig. 12a and b, the VV Kpc is lower than the $\mathrm{HH} \mathrm{Kpc}$ for the $\mathrm{Ku}$ and $\mathrm{C}$ band, and the $\mathrm{C}$-band $\mathrm{Kpc}$ is much lower than the Ku-band Kpc. On the WVC level (Fig. 12c), it shows a similar pattern to SCAT, and generally the instrument noise is lower than $10 \%$ if the outer swath and low wind speeds are excluded.

The SeaWinds Kpc on slice level (Fig. 13a, b) is more constant at a wind speed of 9 and $16 \mathrm{~m} \mathrm{~s}^{-1}$, while it is increasing along with the incidence angle at a low wind speed of $4 \mathrm{~m} \mathrm{~s}^{-1}$. On WVC level, the Kpc is lower than $20 \%$ except for wind speeds below $4 \mathrm{~m} \mathrm{~s}^{-1}$. We note that a random error of $20 \%$ at $4 \mathrm{~m} \mathrm{~s}^{-1}$ is still acceptable in terms of absolute random wind error after wind retrieval.

In general, low wind speeds cause high instrument noise, as expected, and the instrument noise on WVC level is less than $20 \%$ for SCAT, less than $10 \%$ for WindRad, and less than $20 \%$ for SeaWinds, when the outer swath and low wind speeds are excluded. All three scatterometers have a pattern of higher Kpc at the outer swath as compared to the other parts of the swath.

\subsubsection{First rank wind retrieval and 2DVAR performances}

As already known, the first rank wind solution is not always the best solution. However, the more often the first rank so- 


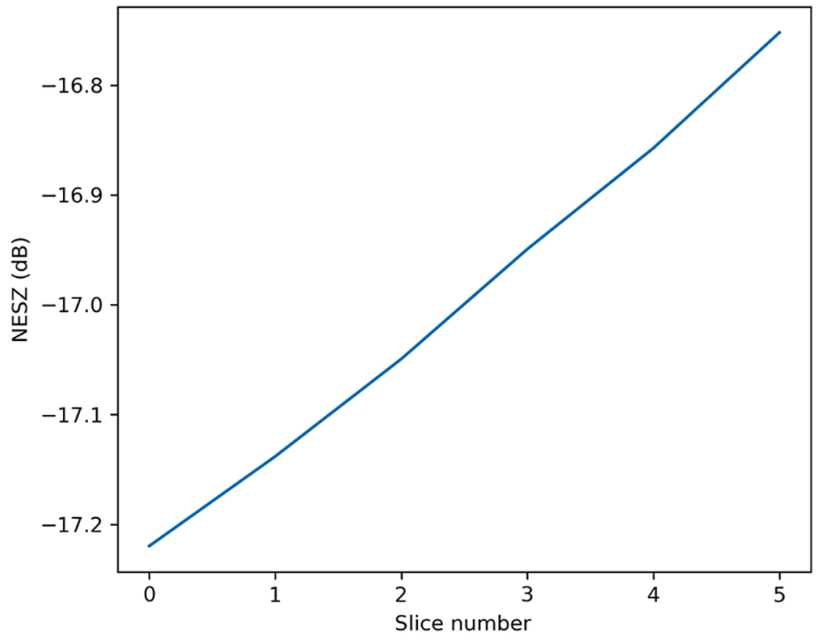

(a)

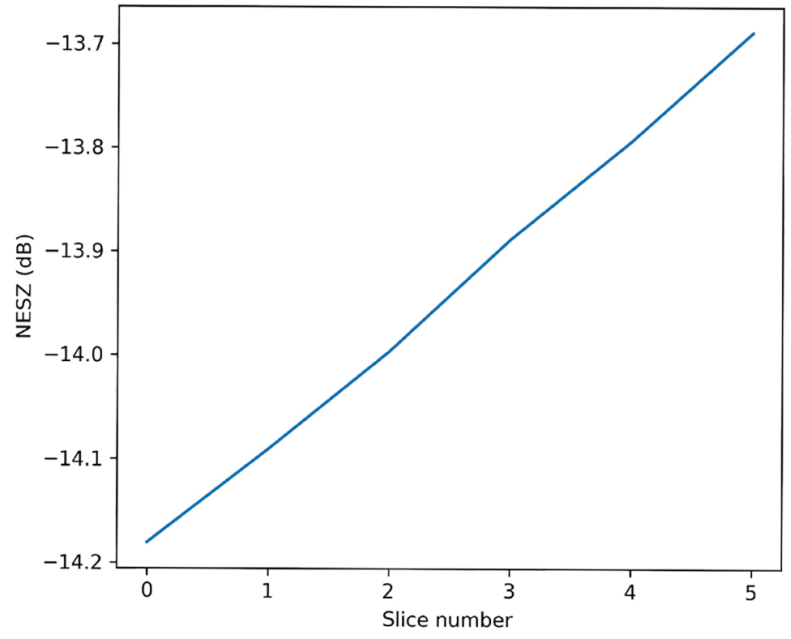

(b)

Figure 5. SeaWinds NESZ distribution as a function of slice number. (a) Ku-band HH polarization. (b) Ku-band VV polarization.

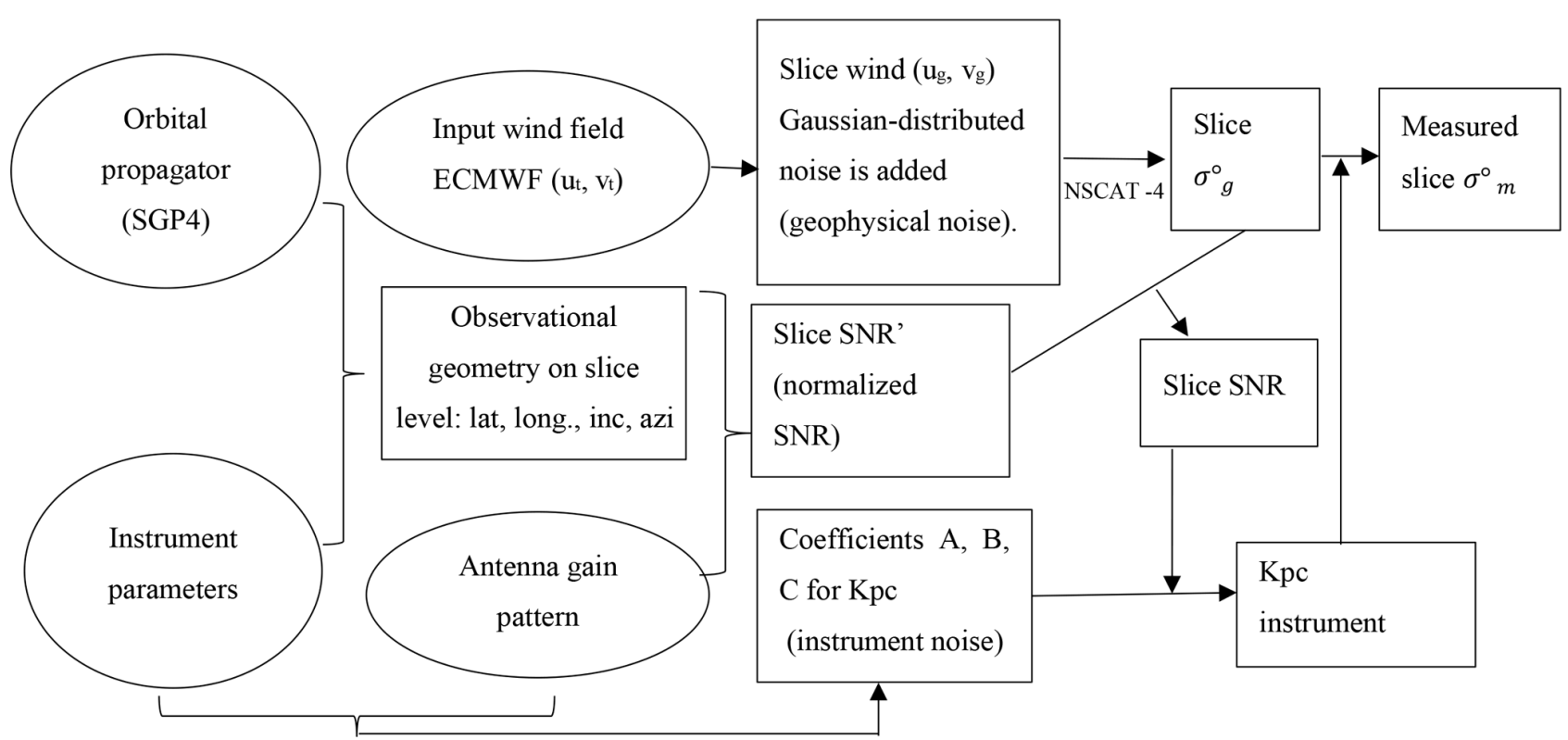

Figure 6. The workflow for generating L1B simulation data.

lution is chosen to be the best solution, the lower the ambiguity in the inverted instrument wind solutions. The quality of the first rank solution thus reflects the ambiguity in the wind measurement system. So, it is chosen for the comparison of the wind retrieval performance on SCAT, Win$\mathrm{dRad}$, and SeaWinds. The difference between first rank solution and 2DVAR performance provides insight into the effects of the wind direction ambiguities on the final selected wind field, which may depend on measurement geometry. 2DVAR with MSS (Multiple Solution Scheme) (Vogelzang, 2013) has been applied in our simulation. A weighted analysis field is constructed by combining the scatterometer ob- servations and a model prediction, and then the one lying closest to the analysis field is selected as the output solution. The problem is solved by minimizing a total cost function that combines both observation and NWP information: $J=J_{\mathrm{obs}}+J_{\mathrm{NWP}}=-2\left[\ln P\left(\boldsymbol{v}_{\boldsymbol{k}} \mid \boldsymbol{x}\right)+\ln P\left(\boldsymbol{x} \mid \boldsymbol{x}_{\boldsymbol{b}}\right)\right]$, where $\boldsymbol{x}$ is the true state of the surface wind field, $\boldsymbol{v}_{\boldsymbol{k}}$ is the possible ambiguous wind solutions, $P\left(\boldsymbol{v}_{\boldsymbol{k}} \mid \boldsymbol{x}\right)$ is the conditional probability of the $\boldsymbol{v}_{\boldsymbol{k}}$ observed given $\boldsymbol{x}$, and $P\left(\boldsymbol{x} \mid \boldsymbol{x}_{\boldsymbol{b}}\right)$ is the conditional probability of surface wind field $\boldsymbol{x}$ given $\boldsymbol{x}_{\boldsymbol{b}}$. Details of the method can be found in de Vries et al. (2005), Vogelzang et al. (2009), Vogelzang (2013). 


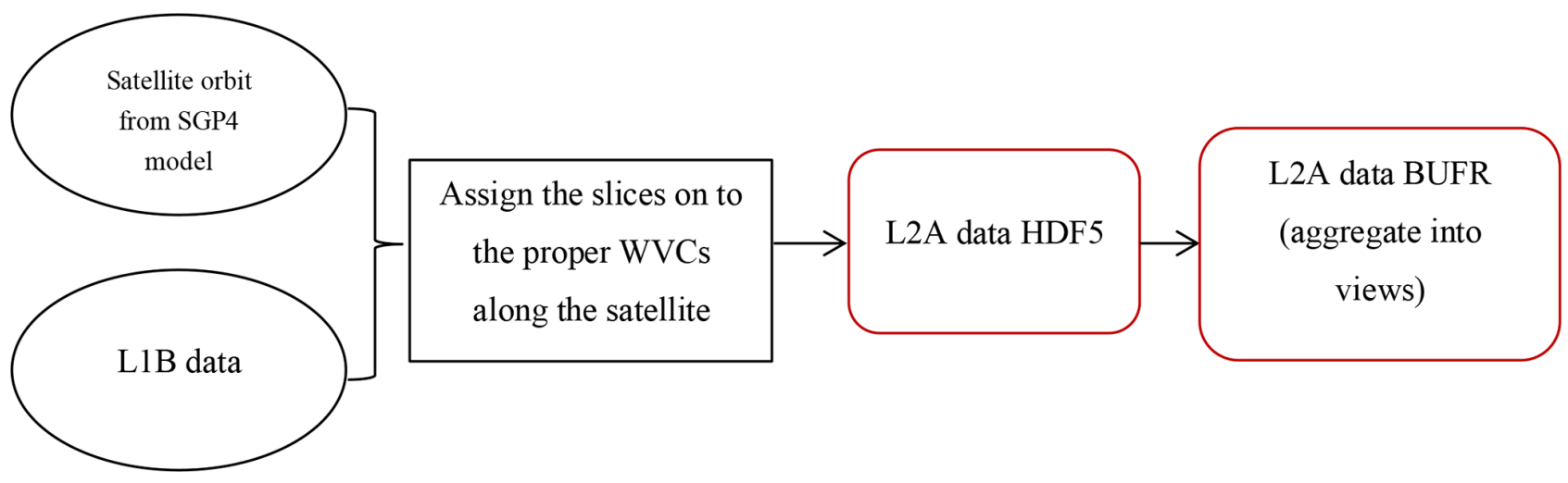

Figure 7. The workflow to assign L1B data to the proper WVCs and aggregate into views.

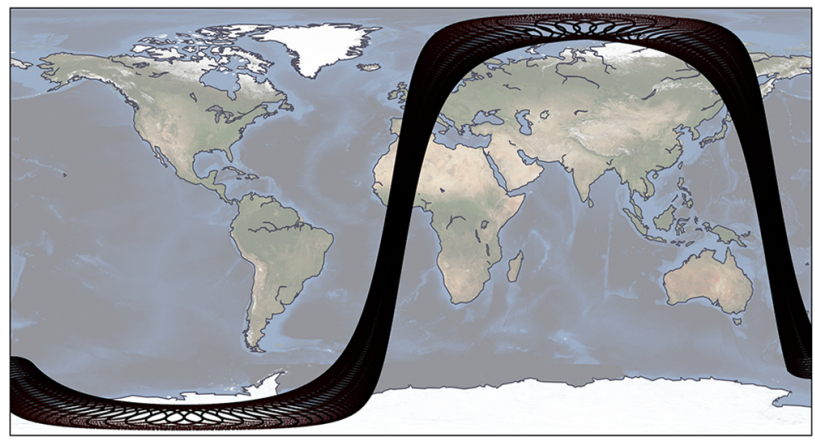

(a)

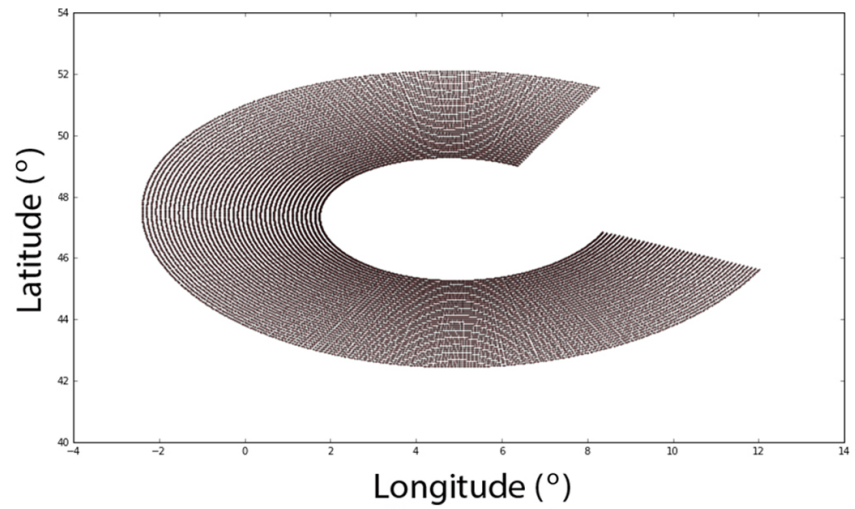

(b)

Figure 8. (a) One simulated satellite orbit for CFOSAT starting from 12 November 2011, with the circular motion of the slice located at the end of each pulse. (b) The zoomed-in location of all slices on the earth.

Comparisons of first rank solution and 2DVAR performances of SCAT, WindRad, and SeaWinds are shown in Figs. 14, 15, and 16. For SCAT, the first rank solution wind field (Fig. 14a) shows poor retrieval quality in the nadir and outer swath, while 2DVAR (Fig. 14b) effectively improves the retrieval results here; a similar improvement occurs for SeaWinds (Fig. 16). The nadir swath of WindRad shows worse wind retrieval quality than the other parts of the swath (Fig. 15a), and 2DVAR is able to correct the false solutions appearing in the first rank solution. Note that the rotation sampling pattern of WindRad is visible as regular disturbances along the swath. This implies that for the same WVC number, different sets of views are collected, depending on the phase of the antenna rotation; hence the wind retrieval performance may vary, e.g., the expected MLE. One aspect needs to be noted: the 2DVAR with MSS works properly in our simulation, but the input wind field of the simulation is ECMWF model data, which is consistent with the 2DVAR background field. Even though a Gaussian-distributed geophysical noise has been added in the input wind field, it still might lead to a selection of wind solutions that tends to be close to the model wind field, and hence it may somewhat overestimate the performance.

\section{Simulation result and wind retrieval performance comparison}

The simulation has been performed on SCAT, WindRad, and SeaWinds with ECMWF model wind data (17 December 2011) as the input wind field. The swath widths for the three instruments are different; in order to make the following figures more comparable, the nadir WVCs of the three instruments are aligned.

\subsection{Wind retrieval performance evaluation}

\subsubsection{Assessments with the input wind field}

Four orbits of data on 17 December 2011 have been generated to be used for the wind retrieval simulation. The contoured histograms in Figs. 17, 18, and 19 provide statistics of the wind speed, wind direction with respect to a wind blowing from the north, and wind components $u$ (eastward) and 
Scat $\mathrm{A}=$ real data $\mathrm{Scat} B=$ simulated data
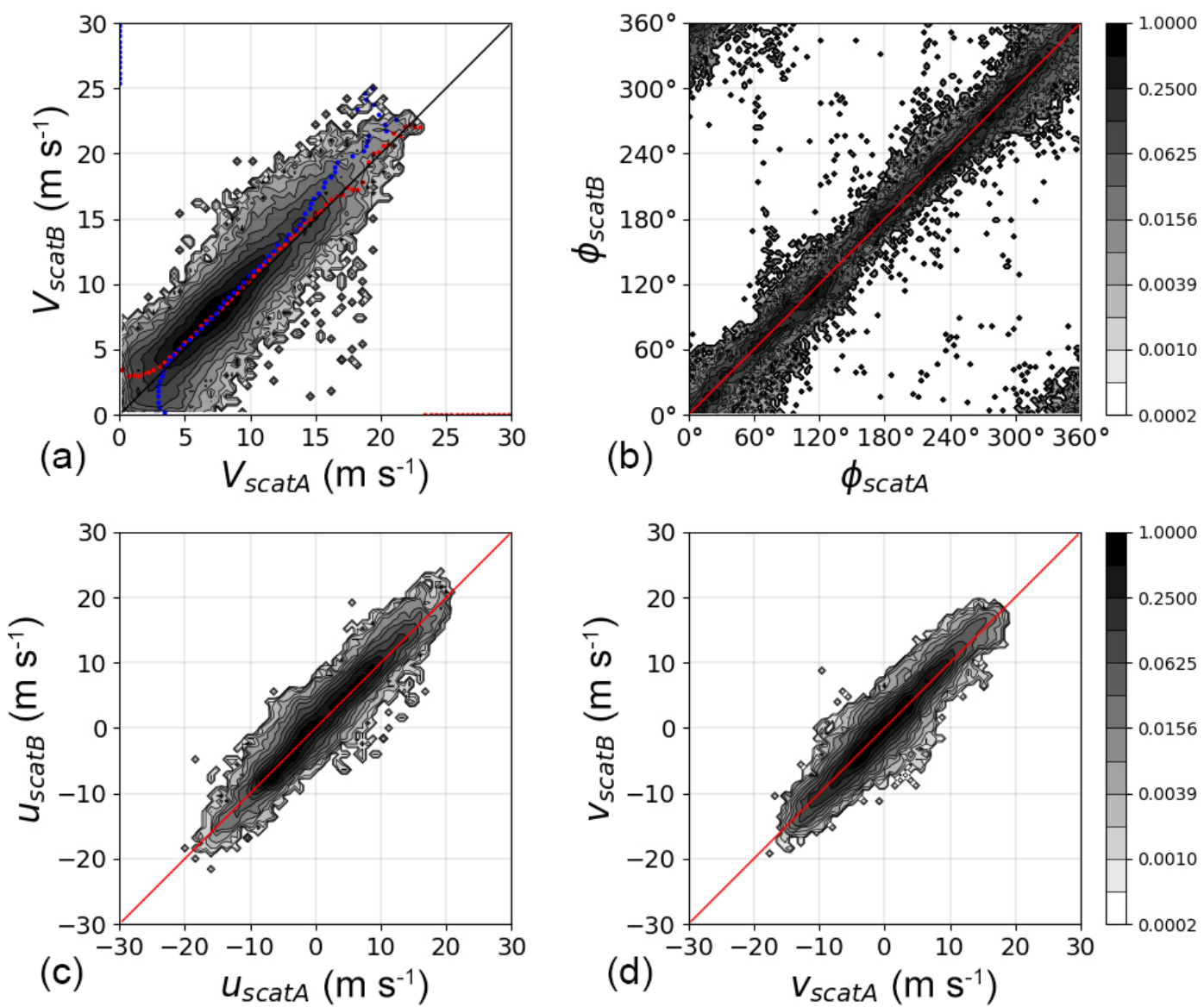

Figure 9. The collocation between SeaWinds (ScatA) and simulated SeaWinds (ScatB) in wind speed (a: red points are the average value as a function of wind speed of ScatA; blue points are the average value as a function of wind speed of ScatB), wind direction (b), $u$ component (c), $v$ component (d).

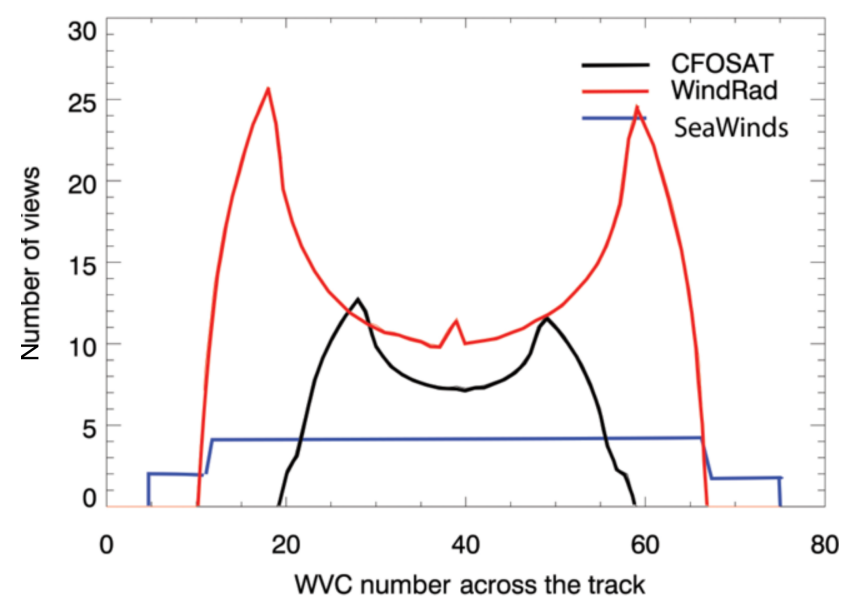

Figure 10. Averaged number of views at the WVCs across the swath. $v$ (northward) versus the variable "true" input wind field for SCAT, WindRad, and SeaWinds. We note that opposing wind solutions will have opposite $u$ and $v$ signs and similar amplitude, and therefore such common ambiguity appears as a cross pattern in the $u$ and $v$ histograms. This ambiguity is directly related to the main double harmonic dependency of the GMF (Wang et al., 2019).

For SCAT (Fig. 17a), the first rank solution of all WVCs across the swath is included. It shows rather poor statistics when compared with the input wind field. However, by simply excluding the WVCs located in the outer swath, the first rank solution quality improves substantially (Fig. 17b). The spread in the wind speeds is reduced, and some derived false wind directions, which are shown as parallel and perpendicular lobes to the true value in the plots, are removed. When the nadir-swath WVCs are also excluded (Fig. 17c), then the wind speed collocation statistics stay almost unchanged as compared to Fig. 17b, while most of the false wind directions perpendicular to the true value are removed. This means that the outer swath contains the most ambiguous wind vector re- 


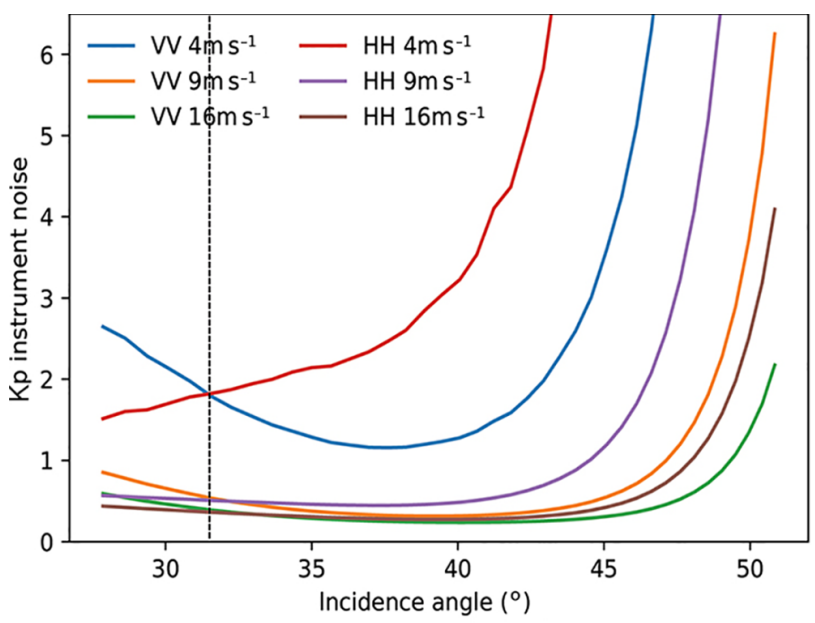

(a)

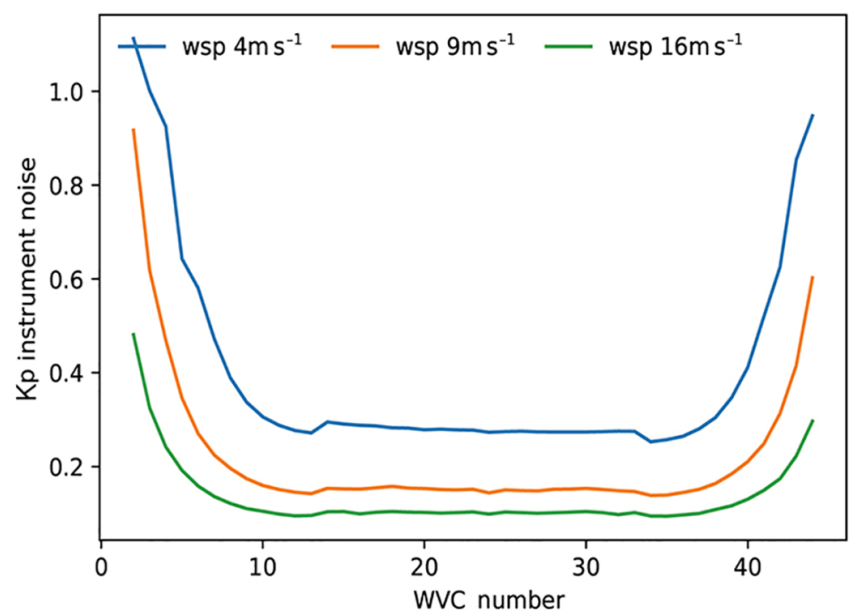

(b)

Figure 11. SCAT instrument noise in ratio $(1$ is $100 \%)$ at 4,9 , and $16 \mathrm{~ms}^{-1}$ on (a) slice level and (b) WVC mean Kp.

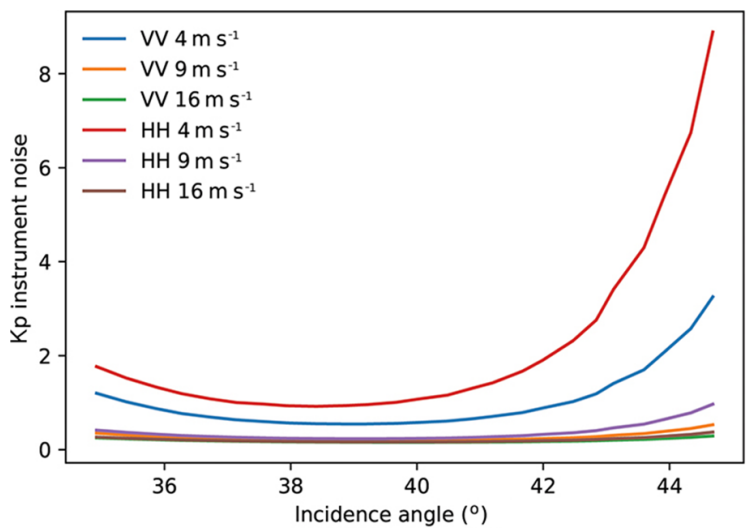

(a)

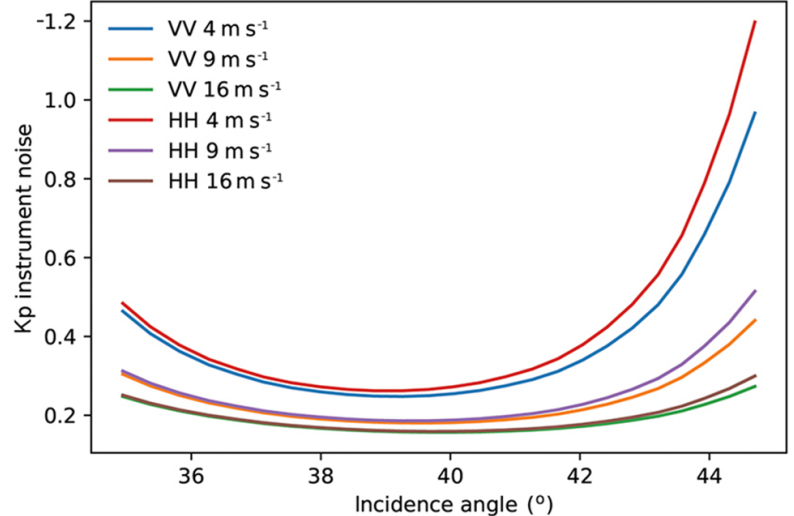

(b)

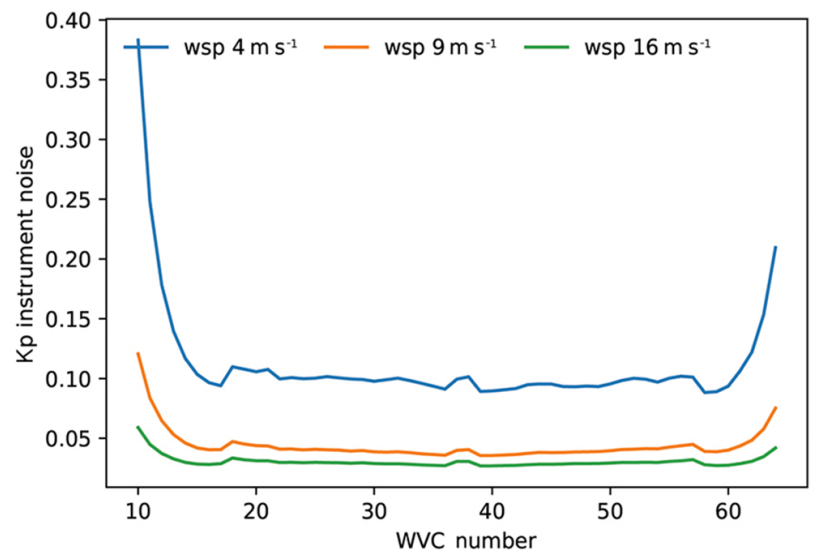

(c)

Figure 12. WindRad instrument noise in ratio (1 is $100 \%)$ at 4,9 , and $16 \mathrm{~ms}^{-1}$ on (a) slice level of the Ku band, (b) slice level of the C band (slices with SNR $<0.05$ are excluded), and (c) WVC mean Kp. 


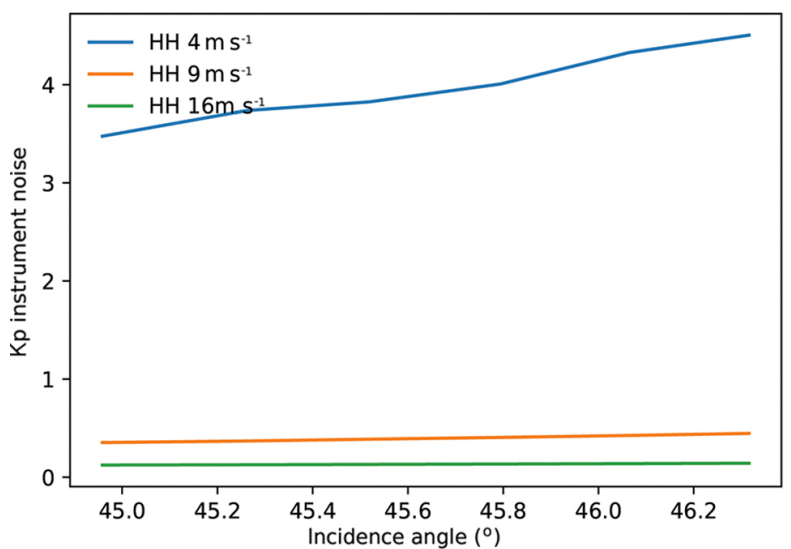

(a)

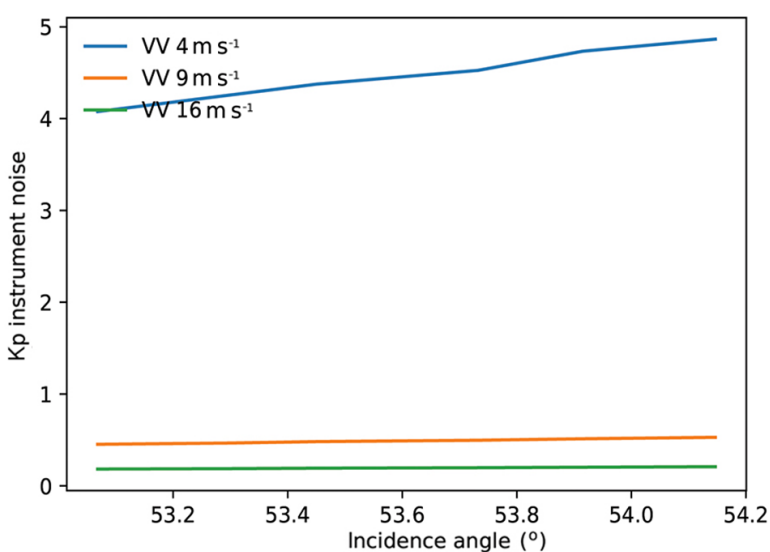

(b)

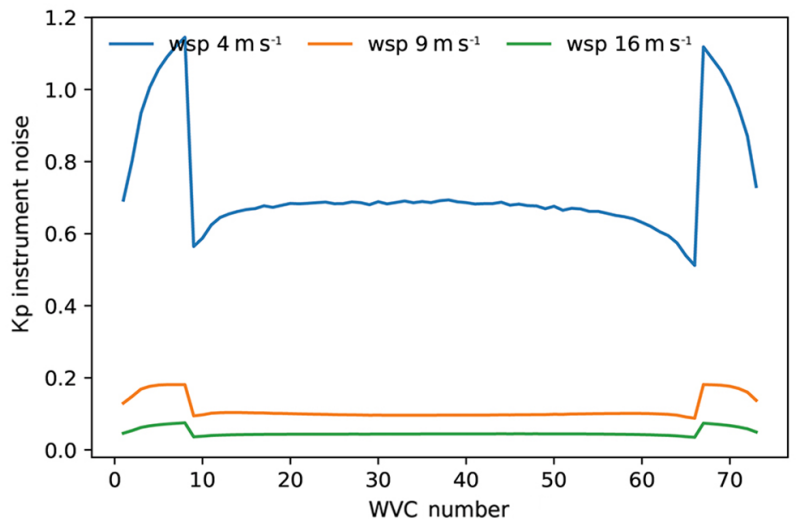

(c)

Figure 13. SeaWinds instrument noise in ratio $(1$ is $100 \%)$ at 4,9 , and $16 \mathrm{~m} \mathrm{~s}^{-1}$ on (a) slice level of Ku-band HH polarization, (b) slice level of Ku-band VV polarization (slices with SNR $<0.05$ are excluded), and (c) WVC mean Kp.

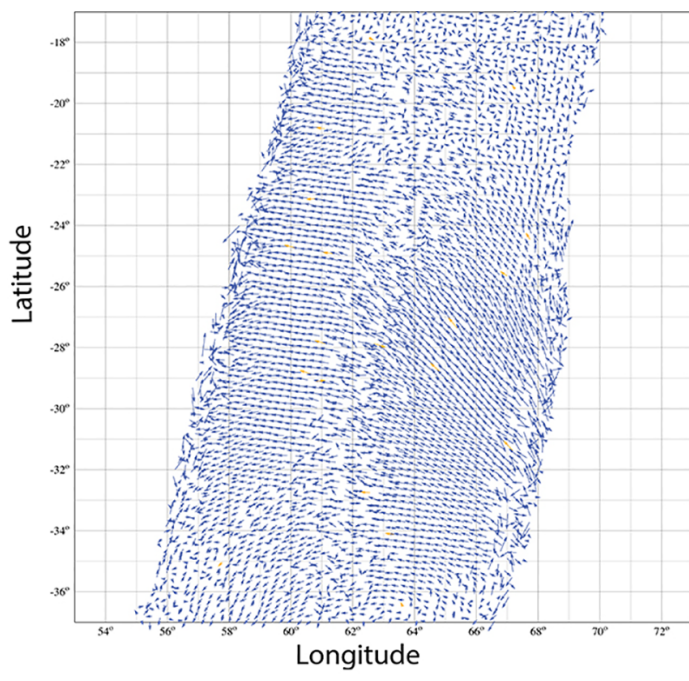

(a)

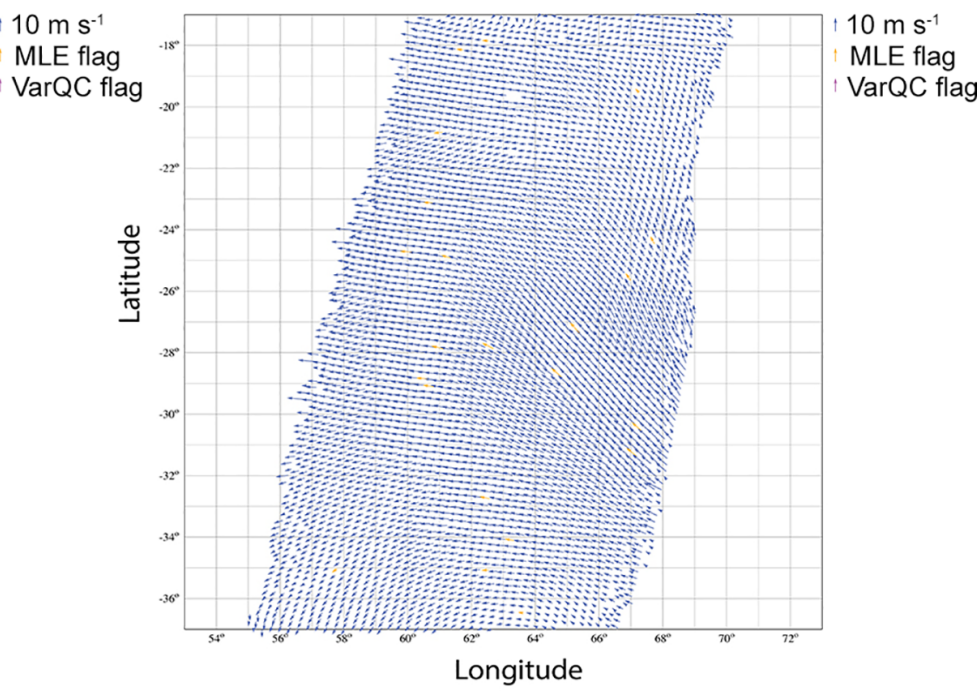

(b)

Figure 14. SCAT-retrieved wind field. (a) First rank solution. (b) 2DVAR result. The orange flags are artificial quality control points and may be ignored. 


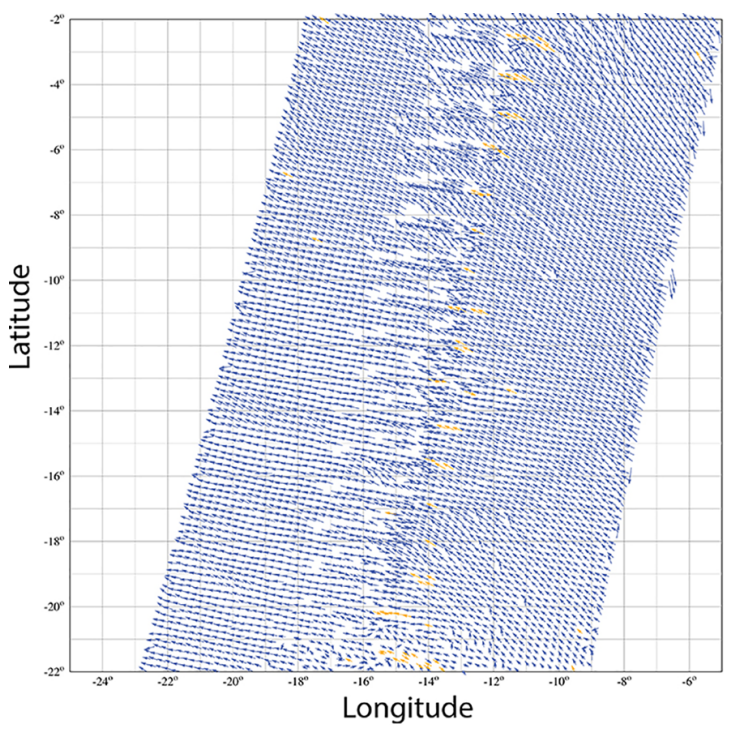

(a)

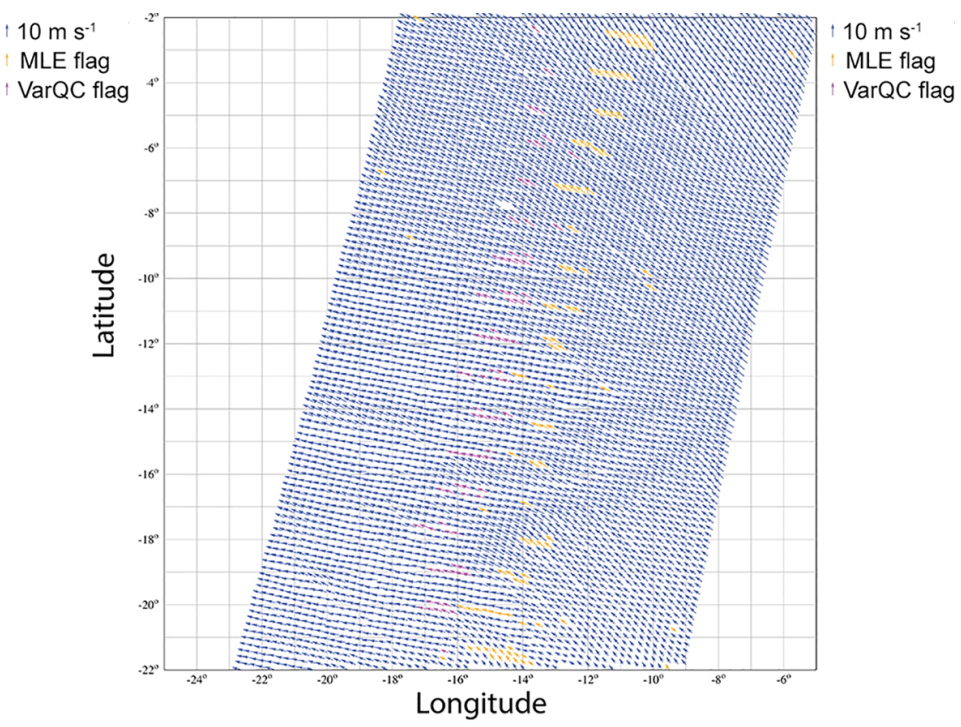

(b)

Figure 15. WindRad-retrieved wind field. (a) First rank solution. (b) 2DVAR result. The orange flags are artificial QC points and may be ignored.

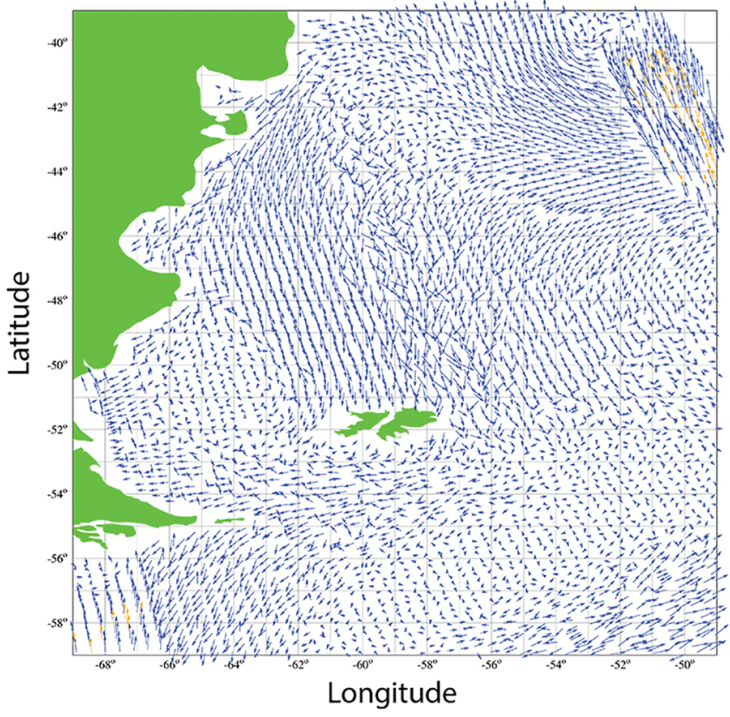

(a)

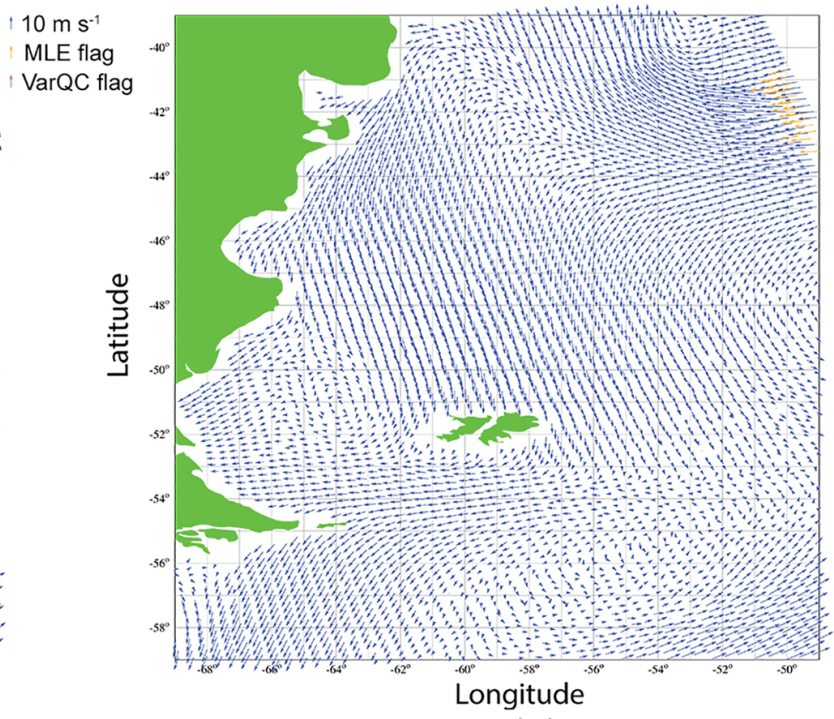

(b)

Figure 16. SeaWinds-retrieved wind field. (a) First rank solution. (b) 2DVAR result. The orange flags are artificial QC points and may be ignored.

sults, while the nadir swath ambiguities cause mainly wind direction errors.

Figure 18a shows the first rank wind retrieval for WindRad with all WVCs, and it shows much better statistics as compared to SCAT (Fig. 17a), due to the availability of twice the number of views in each WVC. Excluding outer WVCs (Fig. 18b) has less effect on the wind retrieval quality for WindRad than for SCAT. The retrieved wind speed shows slightly better statistics, but wind direction statistics stay almost unchanged, which means that the outer WVCs do not have a much larger wind direction ambiguity. On the other hand, when we only exclude nadir WVCs (Fig. 18c), the wind direction retrieval is improved. The average wind speed bias is $0.42 \mathrm{~m} \mathrm{~s}^{-1}$, and the standard deviation of wind direction is $32.21^{\circ}$ (Fig. 18c), while they are $0.51 \mathrm{~m} \mathrm{~s}^{-1}$ and $41.30^{\circ}$ for Fig. 18b, respectively. The last experiment shown for WindRad is with the exclusion of both outer and nadir WVCs (Fig. 18d), with an averaged wind speed bias 


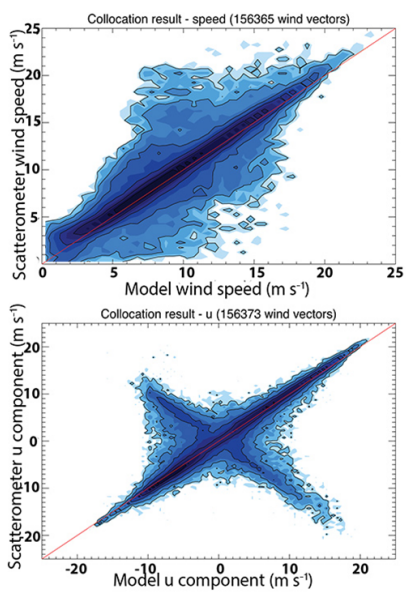

(a)
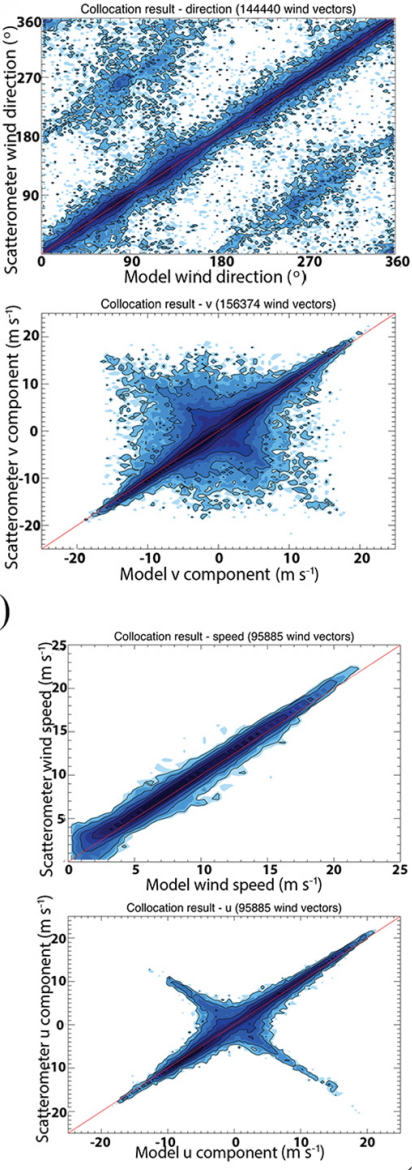
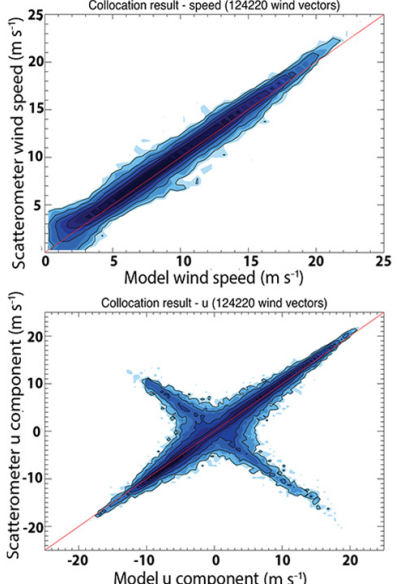

(b)
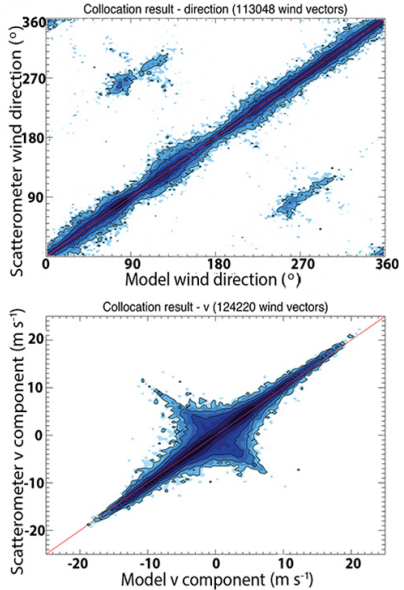

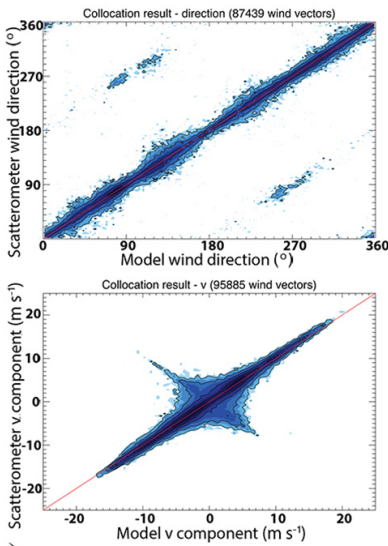

(c)

Figure 17. Contoured histograms of SCAT-retrieved first rank wind solution versus input wind field for four orbits. (a) All WVCs within the swath; (b) excluding the WVCs in the outer swath, for which WVC numbers from 8 to 42 are included; (c) excluding the WVCs in the outer swath and nadir swath, for which WVC numbers from 8 to 17 and 26 to 42 are included. From (a) to (c), upper left: wind speed; upper right: wind direction; lower left: $u$ component; lower right: $v$ component. The contour lines are logarithmic.

of $0.44 \mathrm{~m} \mathrm{~s}^{-1}$ and a standard deviation of wind direction of $35.61^{\circ}$. The largest performance improvement of WindRad occurs when excluding nadir WVCs. The outer swath mainly influences the wind speed retrieval skill, while the nadir swath provides wind direction ambiguity.

SeaWinds's outer swath contains only two views (fore$\mathrm{VV}$ and aft-VV), and in order to process outer swath winds, each of these two views is split into two views based on their azimuth angle (four views in total in the end). Even though there are four views at the outer swath, the limited azimuth diversity leads to more ambiguous wind retrieval results (Fig. 19). The wind retrieval quality of SeaWinds is the poorest one among these three instruments.

The averaged wind retrieval statistics against the input wind field are dominated by the lack of ambiguity removal and nonlinearity. In practice these issues are successfully dealt with in the ambiguity removal step, using prior background information. In the next section we determine figures of merit (FoMs) to compare scatterometer performances with and without such prior information.

\subsubsection{Figures of merit}

The first rank solutions contain ambiguities and because the input wind field is the ECMWF model wind, but without spatially correlated error, it leads to a nearly perfect 2DVAR result, which is unrealistic. In order to further evaluate the wind retrieval performance, the ambiguity of the solutions may be statistically evaluated in the context of generally available background (NWP) information. Figures of merit (FoMs) are a set of parameters to evaluate the wind retrieval quality of different scatterometer concepts, taking into account imprecise, ambiguous, and biased wind solutions. Three FoMs, which are the normalized wind vector rms (root mean square) (VRMS) error, ambiguity susceptibility (AMBI), and systematic error (BIAS), are introduced here based on Rivas et al. (2009). A brief description is given first. 


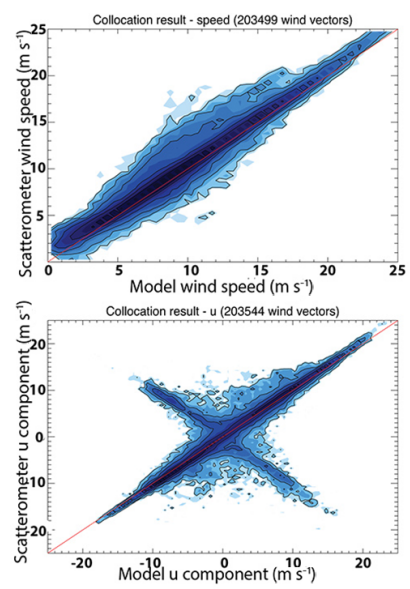

(a)

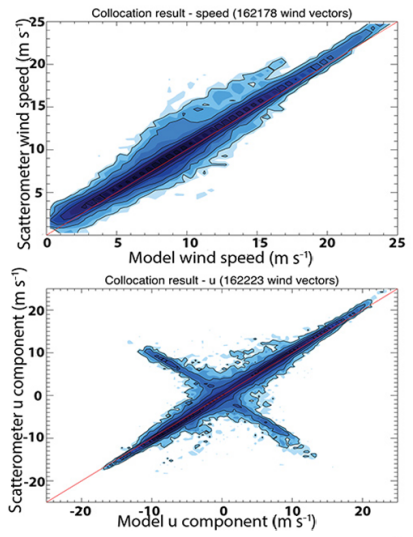

(c)
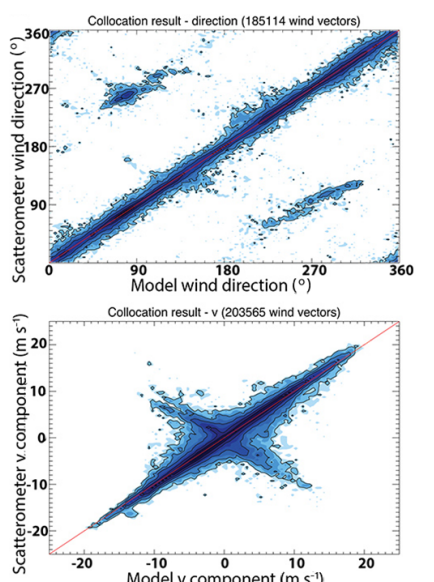

a)
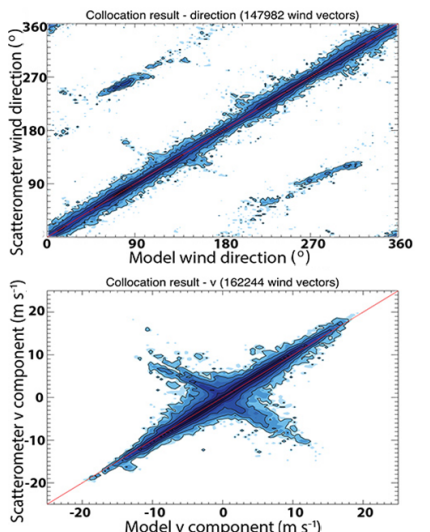

c)
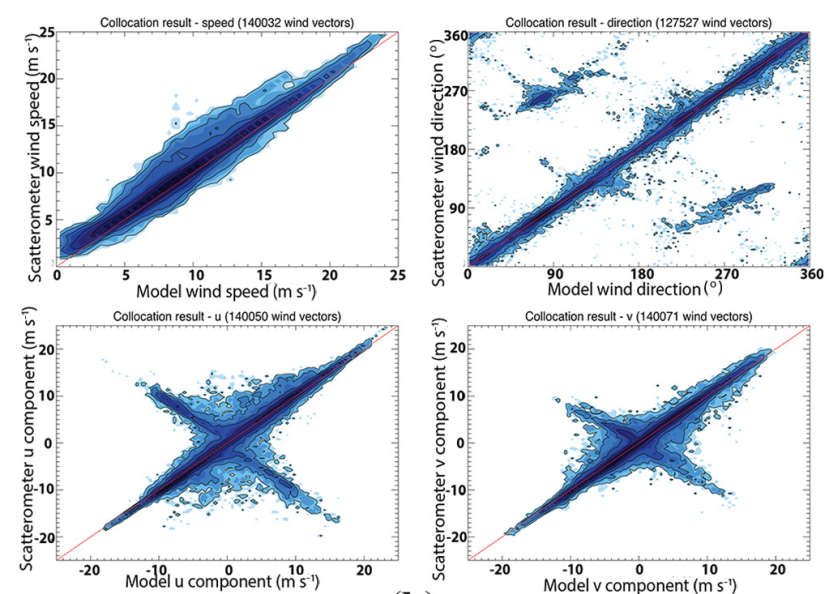

(b)
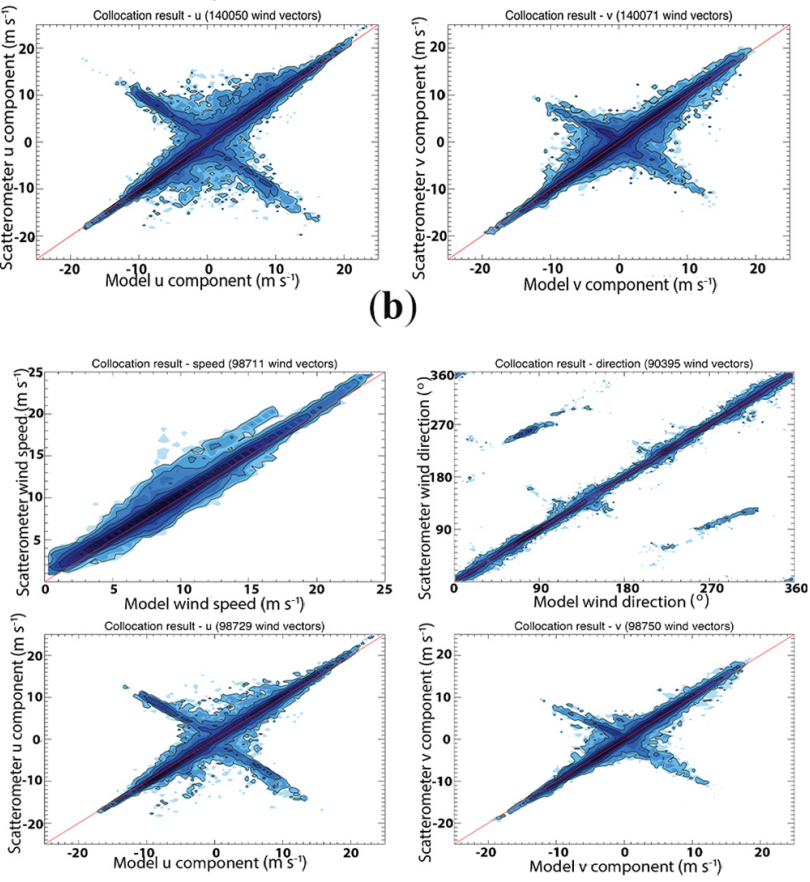

(d)

Figure 18. Contoured histograms of WindRad retrieved first rank wind solution versus input wind field for four orbits. (a) All WVCs within the swath; (b) excluding the WVCs in the outer swath, for which WVC numbers from 20 to 60 are included; (c) excluding the WVCs in the nadir swath, for which WVC numbers from 35 to 45 are included; (d) excluding the WVCs in the outer swath and nadir swath, for which WVC numbers from 20 to 35 and 45 to 60 are included. The four panels in (a)-(d), upper left: wind speed; upper right: wind direction; lower left: $u$ component; lower right: $v$ component. The contour lines are logarithmic.

The VRMS FoM is defined to quantify the ability of the scatterometer wind retrieval to handle ambiguous solutions with a priori NWP model information, such as in 2DVAR, but without actually simulating realistic spatially correlated errors. The input wind field to our simulation is considered as true winds (denoted with $\boldsymbol{v}_{\mathrm{t}}$ ). VRMS quantifies the total simulated wind retrieval error with respect to $\boldsymbol{v}_{\mathrm{t}}$. It is, however, calculated by down-weighting ambiguous wind vector solutions that are very distant from $\boldsymbol{v}_{\mathrm{t}}$, since in practice it is easiest for 2DVAR and other applications to discard such solutions. The down-weighting involves the common prior knowledge in these applications, which is the general NWP background wind component uncertainty, denoted $\sigma_{\mathrm{NWP}}$ and assumed equal for $u$ and $v$. The ambiguous retrieved wind vector distribution, expressed in the wind probability $P_{\text {obs }}\left(\boldsymbol{v} \mid \boldsymbol{v}_{\mathrm{t}}\right)$, is multiplied by a Gaussian probability distribution $P_{\mathrm{NWP}}\left(\boldsymbol{v}-\boldsymbol{v}_{\mathrm{t}}\right)$ centered at the input wind field and with a variance $\sigma_{\mathrm{NWP}}^{2} \sim 5 \mathrm{~m}^{2} \mathrm{~s}^{-2}$ in both wind components.
The VRMS FoM is subsequently obtained by normalizing this expression by the prior NWP VRMS error:

$\mathrm{FoM}_{\mathrm{VRMS}}=\frac{\mathrm{rms}_{\mathrm{obs}}}{\mathrm{rms}_{\mathrm{NWP}}}$,

where

$\mathrm{rms}_{\mathrm{obs}}=\left(\sqrt{\int\left|\boldsymbol{v}-\boldsymbol{v}_{\mathrm{t}}\right|^{2} P_{\mathrm{obs}}\left(\boldsymbol{v} \mid \boldsymbol{v}_{\mathrm{t}}\right) \times P_{\mathrm{NWP}}\left(\boldsymbol{v}-\boldsymbol{v}_{\mathrm{t}}\right) d^{2} v}\right)$

and

$\operatorname{rms}_{\mathrm{NWP}}=\left(\sqrt{\int\left|\boldsymbol{v}-\boldsymbol{v}_{\mathrm{t}}\right|^{2} P_{\mathrm{NWP}}\left(\boldsymbol{v}-\boldsymbol{v}_{\mathrm{t}}\right) d^{2} v}\right)=\sqrt{2} \sigma_{\mathrm{NWP}}$.

VRMS quantifies the wind solution's relative rms about the true wind with respect to the general prior background uncertainty. If its value is 1 , then the wind retrieval failed to 

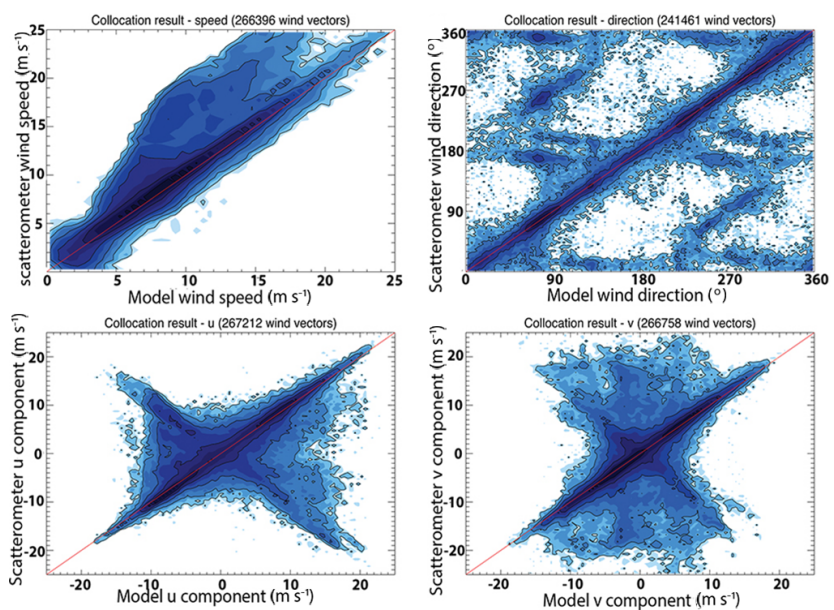

(a)
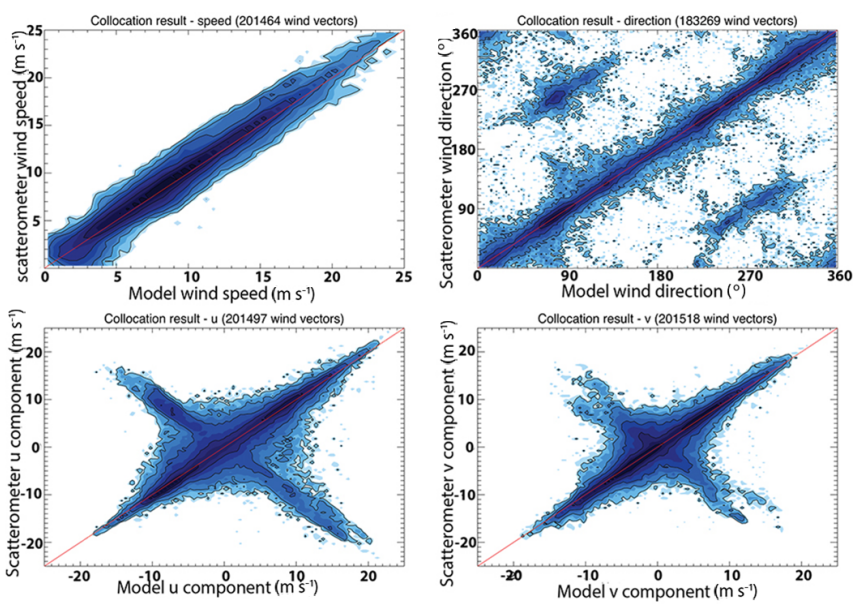

(b)

Figure 19. Contoured histograms of SeaWinds retrieved first rank wind solution versus input wind field for four orbits. (a) All WVCs within the swath; (b) excluding the WVCs in the outer swath, for which WVC numbers from 10 to 65 are included. From (a) to (b), upper left: wind speed; upper right: wind direction; lower left: $u$ component; lower right: $v$ component. The contour lines are logarithmic.

provide new and useful information in the wind field, i.e., corresponding to $P_{\mathrm{obs}}\left(\boldsymbol{v} \mid \boldsymbol{v}_{\mathrm{t}}\right)=$ constant.

On the other hand, AMBI is defined to quantify the ability of the scatterometer and its processing to handle ambiguous solutions without a priori NWP model information. It is a ratio of the wind solution output falling outside the general prior wind field constraint, relative to the output falling inside the prior wind field constraint. The lower the ratio, the better the AMBI FoM, where $P_{\mathrm{NWP}, \max }$ is the maximum probability of $P_{\mathrm{NWP}}\left(\boldsymbol{v}-\boldsymbol{v}_{\mathrm{t}}\right)$.

$\mathrm{FoM}_{\mathrm{AMBI}}=\frac{\int P_{\mathrm{obs}}\left(\boldsymbol{v} \mid \boldsymbol{v}_{\mathrm{t}}\right) \times\left(P_{\mathrm{NWP}, \max }-P_{\mathrm{NWP}}\left(\boldsymbol{v}-\boldsymbol{v}_{\mathrm{t}}\right)\right) d^{2} v}{\int P_{\mathrm{obs}}\left(\boldsymbol{v} \mid \boldsymbol{v}_{\mathrm{t}}\right) \times P_{\mathrm{NWP}}\left(\boldsymbol{v}-\boldsymbol{v}_{\mathrm{t}}\right) d^{2} v}$

BIAS quantifies the systematic vector wind bias, again in the context of the background prior, which is the shift of the average location of the output wind solution away from the location of the prior wind caused by skewness in the output wind solutions (Eq. 4).

$\mathrm{FoM}_{\mathrm{BIAS}}=\int\left(\boldsymbol{v}-\boldsymbol{v}_{\mathrm{t}}\right) \cdot P_{\mathrm{obs}}\left(\boldsymbol{v} \mid \boldsymbol{v}_{\mathrm{t}}\right) \times P_{\mathrm{NWP}}\left(\boldsymbol{v}-\boldsymbol{v}_{\mathrm{t}}\right) d^{2} v$

The wind retrieval is a nonlinear problem, and the output wind error depends on the true wind vector (wind speed and direction distribution). In order to minimize this dependence, the calculated FoMs are averaged over a climatology of wind inputs with uniformly distributed directions and wind speeds ( 3 to $16 \mathrm{~m} \mathrm{~s}^{-1}$ ) following a Weibull distribution with a maximum around $8 \mathrm{~ms}^{-1}$ (Liu et al., 2008). The input wind speeds are from 3 to $16 \mathrm{~ms}^{-1}$ with steps of $1 \mathrm{~m} \mathrm{~s}^{-1}$, and the input wind directions are from 0 to $360^{\circ}$ with steps of $10^{\circ}$. Each wind speed and wind direction combination contains the equivalent number of WVCs from the same orbit.
Figure 20 gives the three FoM comparisons of SCAT, Win$\mathrm{dRad}$, and SeaWinds as a function of the WVC positions in the swath. Overall, the wind retrieval performance of the rotating fan-beam instruments is better than the pencil-beam instrument, while the outer and nadir swaths of the three instrument types yield a poorer performance than the sweet swaths. The outer swath of SeaWinds only has two independent views, which result in very ambiguous winds and the worst simulated wind retrieval quality. The wind retrieval quality across the swath strongly depends on the location of the WVC; it degrades substantially in the outer and nadir swaths as expected. The outer swath has worse quality than the nadir swath for both SCAT and SeaWinds, whereas these two regions show comparable wind retrieval quality for Win$\mathrm{dRad}$. Although the number of views in the sweet swath for WindRad is twice the number for SCAT (Fig. 10), the wind retrieval quality is not improved as expected, but it shows very similar quality to SCAT. The elevated values for AMBI and BIAS indicate that, despite the high number of views, the wind retrieval tends to be not well determined and slightly nonlinear. At the same time, the quality in the outer swath of WindRad shows very pronounced improvement with respect to SCAT, due to the increased number of available views.

Figure 21 illustrates the VRMS as a function of wind direction and WVC location at $9 \mathrm{~m} \mathrm{~s}^{-1}$ wind speed. The wind retrieval performance across the swath for all wind directions gives the same pattern as described above with some modulations at different wind direction. There is one different feature occurring for WindRad. The VRMS at nadir swath shows higher values than in the outer swath, which is opposite to SCAT and SeaWinds. AMBI and BIAS (not shown here) have similar patterns to VRMS. 


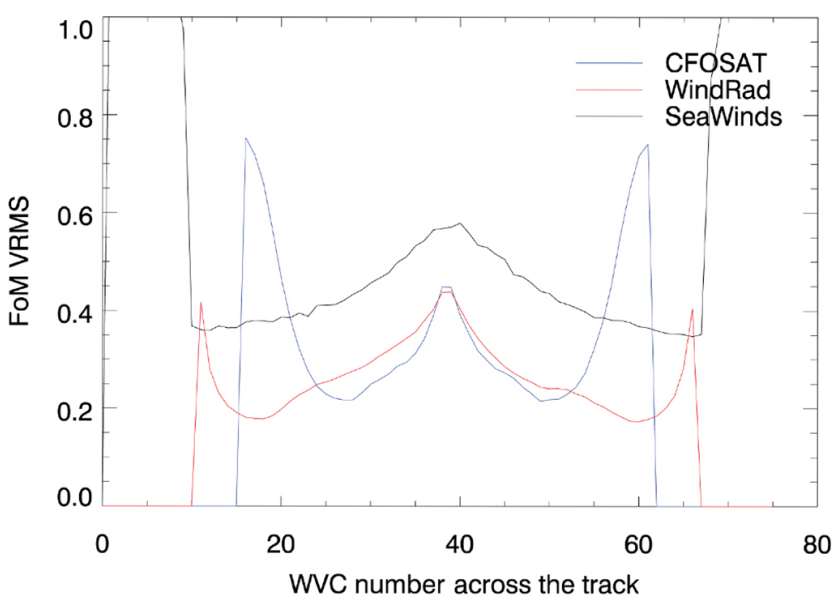

(a)

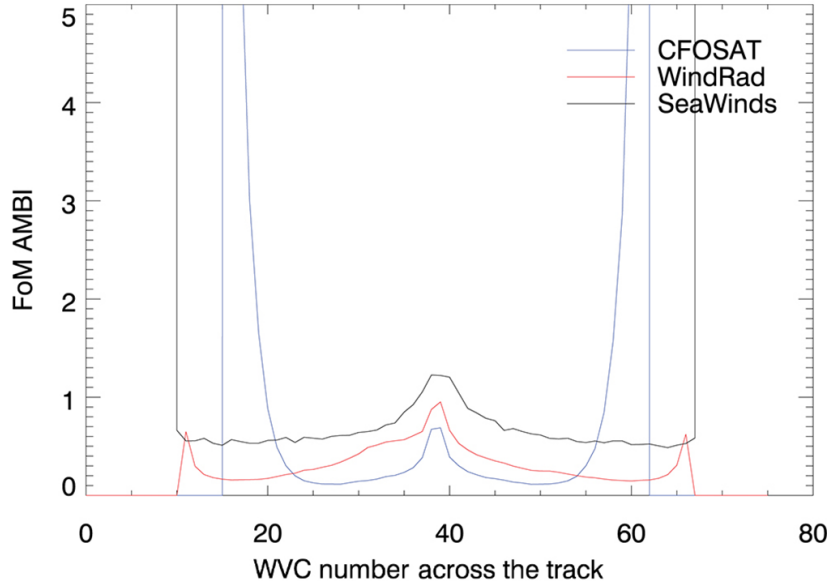

(b)

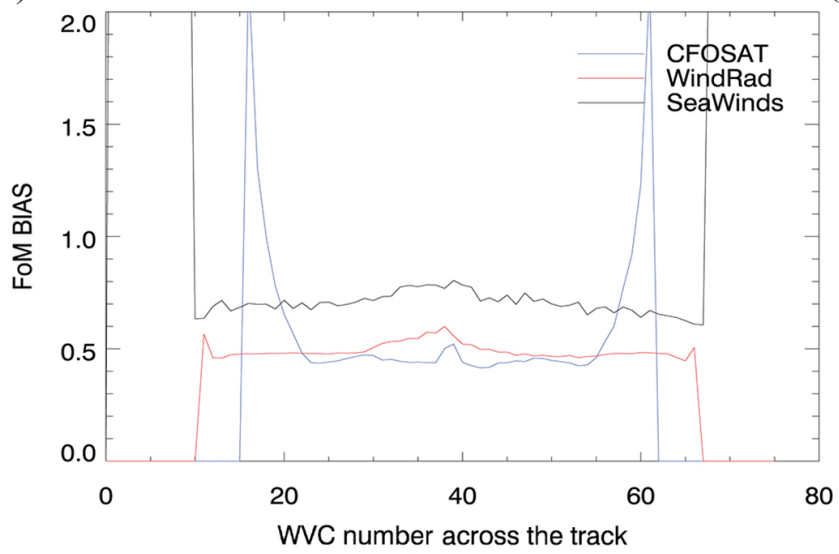

(c)

Figure 20. FoM results of SCAT, WindRad, and SeaWinds. (a) VRMS comparison. (b) AMBI comparison. (c) BIAS comparison.

\subsubsection{Wind direction bias}

Wind direction bias between the wind retrieval result (2DVAR result) and the ECMWF model wind has been evaluated as a function of WVC and relative wind direction, using 15 orbits. The relative wind direction means the retrieved wind direction relative to the satellite motion direction. In this evaluation, we are able to see the wind direction bias with respect to the true direction at all the WVCs (Fig. 22). No matter whether the biases are negative or positive, both signs indicate that the wind directions have a tendency to be closer to the satellite motion direction, and if the wind direction bias is averaged over all the relative wind directions, a small value of the bias remains.

SeaWinds gives stronger bias both on the outer swath and nadir swath (Fig. 22b), while the nadir swath of SCAT gives weaker bias compared to the outer swath due to the increased number of views (Fig. 22a). For WindRad, when the retrieved wind direction is close to satellite motion direction (relative wind direction is 0 ), it shows rather strong negative and positive bias, but the nonbiased area for WindRad is larger than it is in SCAT and SeaWinds. This phenomenon can also be observed with real data from SCATSAT (Wang et al., 2019). This retrieved wind direction preference might be caused by the retrieval method.

\section{Discussion}

Our results confirm that the wind retrieval quality of Ku-band rotating-beam scatterometers (rotating fan-beam and rotating pencil-beam) varies according to the location of the WVCs across the swath, and the outer and nadir swaths show generally lower wind retrieval skill than the sweet swath. The wind retrieval comparisons suggest that WindRad gives the best wind retrieval quality of the three scatterometer types, although its increased number of views does not always result in further wind retrieval quality improvement, particularly not in the sweet swath.

For the rotating fan-beam and rotating pencil-beam instruments, FoMs give quite a clear wind retrieval quality comparison. In general, both rotating systems have the same performance pattern across the track as mentioned above, while the rotating fan-beam system has a better performance for 


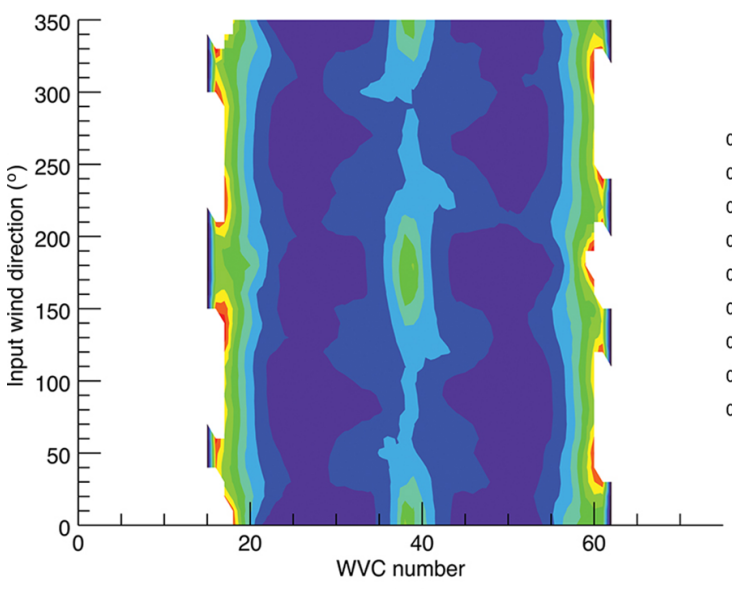

(a)

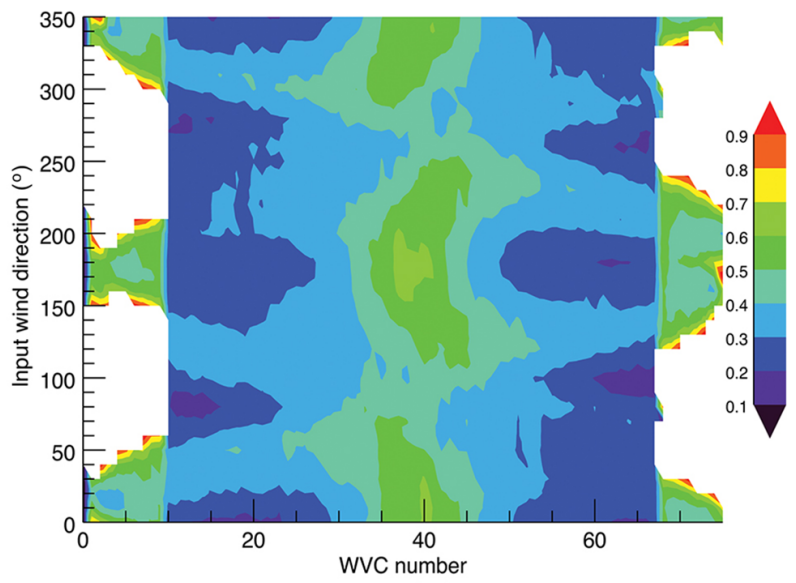

(b)

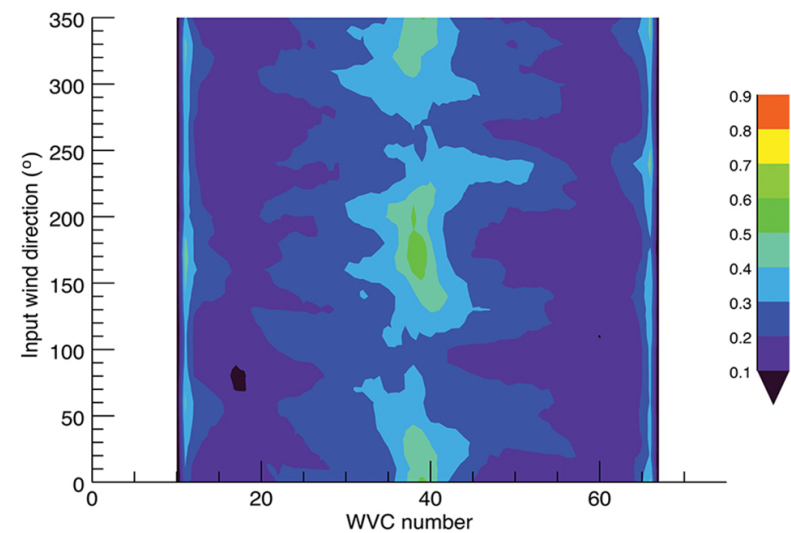

(c)

Figure 21. FoM VRMS map as a function of across-track location and wind direction (wind speed is $9 \mathrm{~m} \mathrm{~s}^{-1}$ ). (a) SCAT. (b) SeaWinds. (c) WindRad.

all the FoMs compared to the pencil-beam system through all WVCs, and the nadir swath tends to spread larger for the pencil-beam type. The obvious reason is that the pencil-beam type classified the views as fore and aft with $\mathrm{HH}$ and $\mathrm{VV}$ polarization, which are a maximum of four views in the sweet swath, while for the fan-beam type it is possible to ensure that the number of views and the diversity of the geometry are high due to its fan shape.

Prior work on SCAT and WindRad mainly focused on the instrument configuration choices and tests with various settings of pulse frequency, polarization, rotating speed, and transmitted peak power, etc. (Lin et al., 2000a, 2002; Lin and Dong, 2011). The main wind retrieval performance characteristics of these two-rotating fan-beam scatterometers, as obtained in these papers, are in line with our study with respect to sweet swath, nadir swath, and outer swath performance. SCAT has been compared with SeaWinds (Lin and Dong, 2011) in an end-to-end simulation, and now we add a cross comparison among SCAT, WindRad, and SeaWinds in the same simulation framework as before.
WindRad shows distinguished and new wind retrieval features in our study with respect to SCAT and SeaWinds. The outer swaths of SCAT and SeaWinds clearly provide the worst wind retrieval skill as compared to nadir, but for WindRad this does not occur. WindRad gives very similar wind retrieval quality in the nadir and outer swaths according to its FoM (Fig. 20). However, the spread of the WindRad FoM values are largest in the inner swath (Fig. 21), and excluding the inner swath leads to a better wind retrieval as compared to excluding the outer swath. This is opposite to SCAT and SeaWinds, for which performance increases most when excluding the outer swath.

Increasing the number of views and azimuth diversity leads to an improved wind retrieval. While this is generally true, comparing SCAT and WindRad, the increased number of WindRad views on their own provides a strong improvement in the outer swath, but it appears not to be effective in the sweet and nadir swath. The azimuths in the nadir swath are always either looking forward of the satellite track or looking backward. The additional views in this case will still have similar azimuths, and these are not effective in improv- 


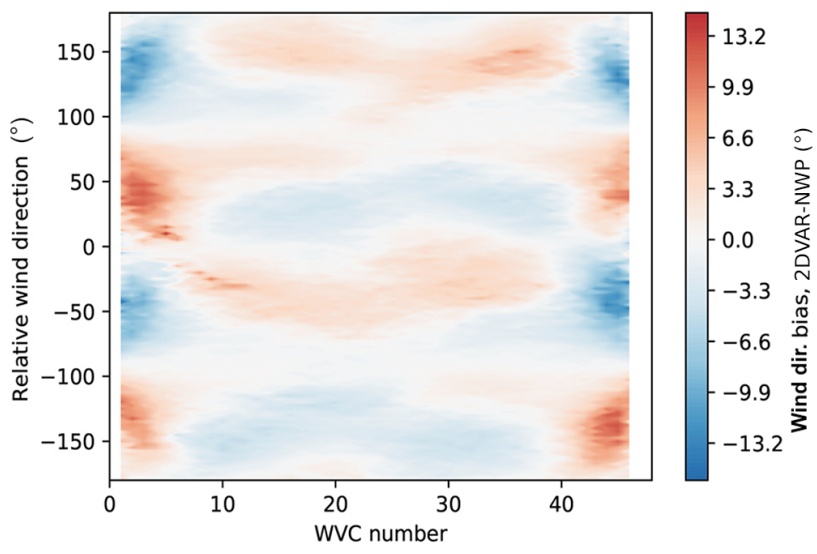

(a)

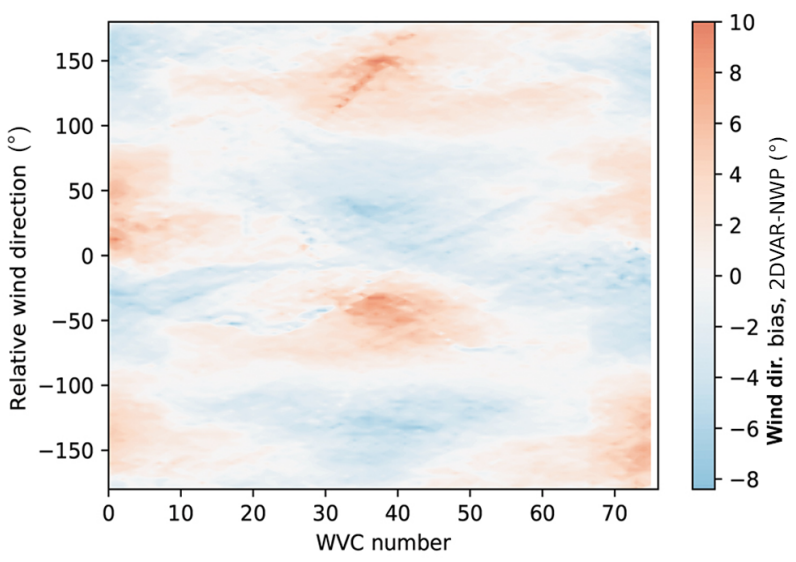

(b)

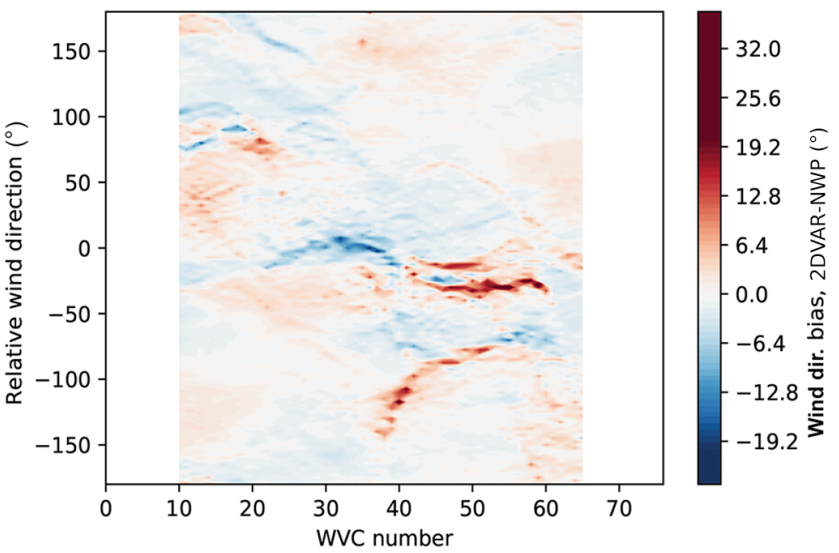

(c)

Figure 22. Wind direction bias between wind retrieval result and true wind as a function of WVC number and the relative wind direction. (The $y$ axis is the retrieved wind direction relative to the satellite motion direction. The color scale is consistent for easy comparison; all the values outside $[-20,20]$ are marked as dark blue and dark red.) (a) SCAT. (b) SeaWinds. (c) WindRad.

ing the azimuth diversity. In the sweet swath, there are up to 18 views in the WVCs, leading to a more diverse observation geometry.

One question is raised here: the relationship between the number of views and their diversity. It seems that the views with similar azimuth angle and the same polarization do not really add diversity into the system, which means they will not improve the wind retrieval result. Such views in the rotating pencil-beam scatterometer are averaged into one view without affecting the wind retrieval. Will we get the same effect for rotating fan-beam scatterometers? In order to investigate this, an experiment was done for SCAT in which the views with azimuth angle difference within $5^{\circ}$ are averaged together into one super view, and the other parts of the wind retrieval are kept the same. This averaging procedure influences the nadir swath strongest since there are only forward and backward azimuth angles (Fig. 23), and the number of views has been reduced according to the similarity of the azimuth angle. The same wind retrieval procedure is per- formed afterwards, and the results are shown in Fig. 24. The wind retrieval result with all WVCs (Fig. 24a) looks quite similar to the wind retrieval result without azimuth averaging (Fig. 17a). However, the wind retrieval results get worse when excluding outer WVCs (Figs. 24b and 17b) and excluding both outer and nadir WVCs (Figs. 24c and 17c). This leads to a conclusion that the averaging of the number of views with similar azimuth angle into a single view is not able to improve the wind retrieval for a rotating fan-beam system, and even if the azimuth diversity of the views is similar, it still adds geometry diversity into the wind retrieval procedure, which leads to a better retrieval result.

The incidence angle range of SCAT, with almost $25^{\circ}$ between lowest and highest incidence angle, is much broader than that of WindRad, which is approximately $10^{\circ}$. Moreover, the minimum SCAT incidence angle at $25^{\circ}$ is about $10^{\circ}$ lower than that from WindRad. This implies that, while moving away from nadir, the azimuth diversity of SCAT increases much faster than that of WindRad, hence the steep perfor- 


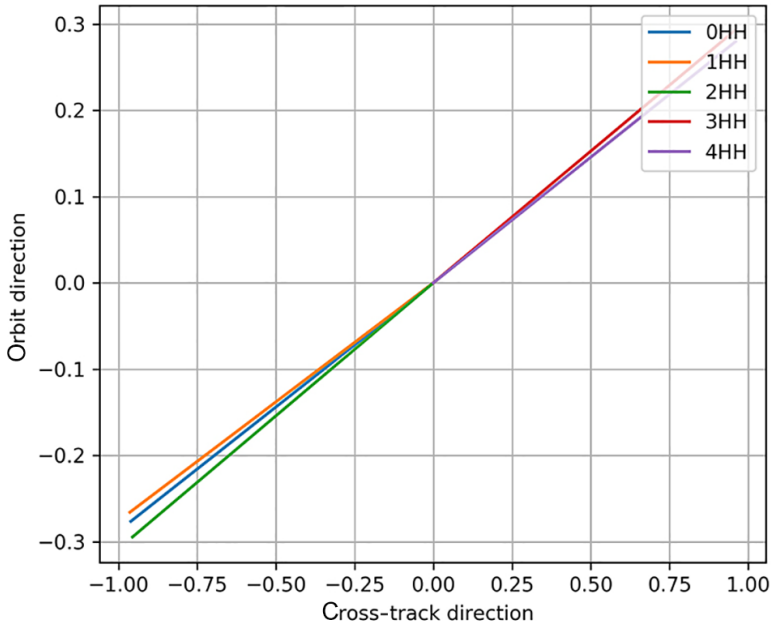

(a)

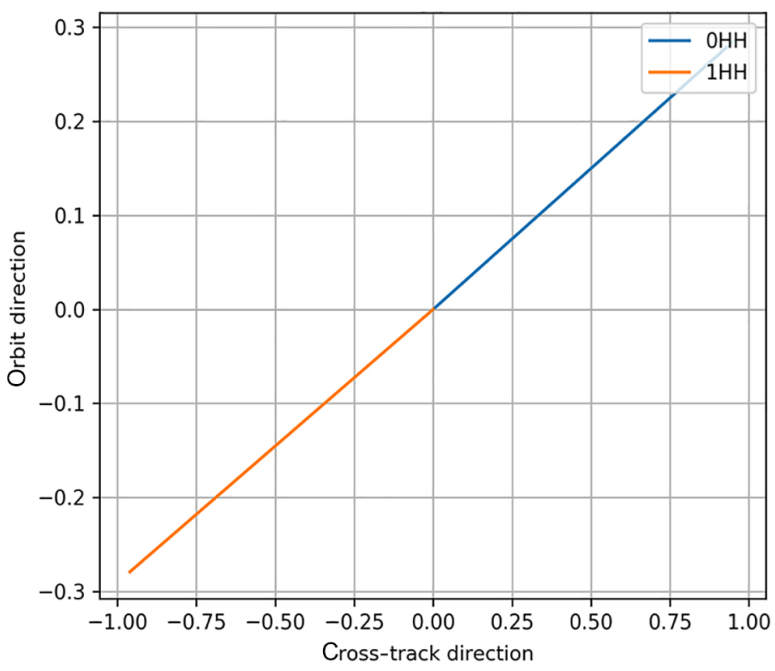

(c)

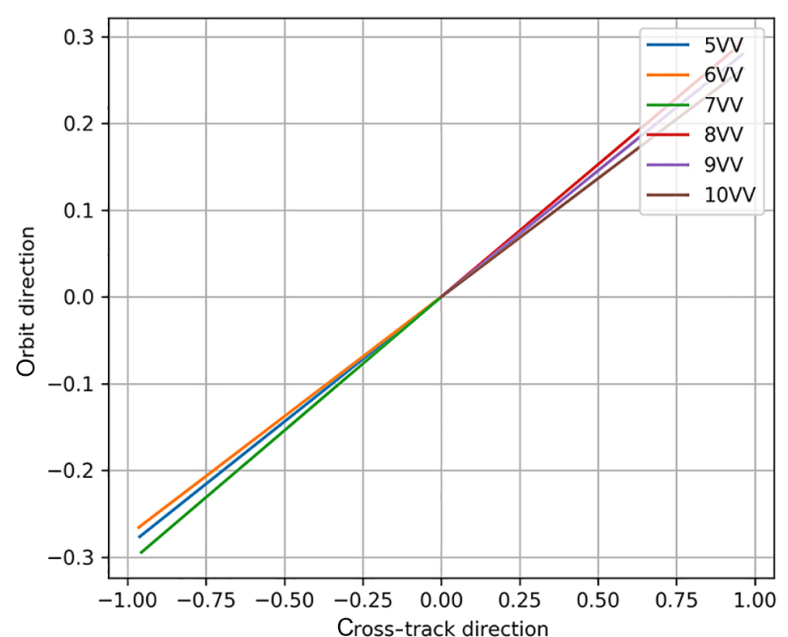

(b)

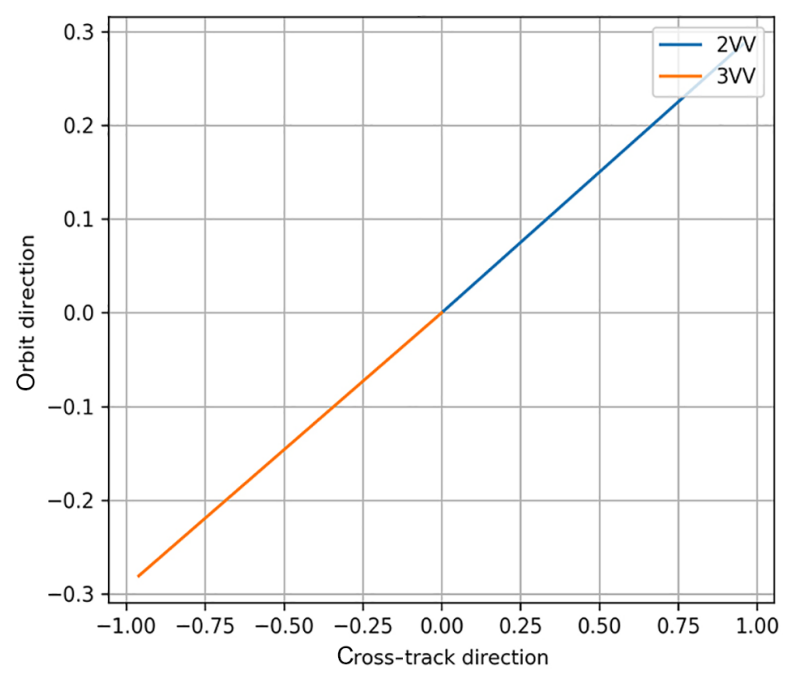

(d)

Figure 23. SCAT azimuth angle distribution of the WVC located at the nadir swath. (The values of $x$ axis and $y$ axis are for the angle display; they do not have actual meanings. The $x$ axis is the cross-track direction, and the $y$ axis is the satellite moving direction.) (a) Azimuth angles of the views with $\mathrm{HH}$ polarization. (b) Azimuth angles of the views with VV polarization. (c) Azimuth angles of the views with HH polarization (views with similar azimuth angles are aggregated into one view). (d) Azimuth angles of the views with VV polarization (views with similar azimuth angles are aggregated into one view).

mance increase for SCAT when moving away from nadir. On the other hand, the many channels on WindRad and its fan beam add a lot of additional views and azimuth diversity near the outer swath, as compared to SCAT and SeaWinds, hence the outstanding outer swath performance of WindRad. We found that the number of slices located in the outer swath is the least, and the geometrically unbalanced $\sigma^{\circ}$ distribution within the views of a WVC is one of the reasons for the low retrieval quality. The instrument noise also contributes, and it is lower for WindRad than it is for SCAT on average.

All in all, the wind retrieval is substantially better in the outer swath for WindRad. We also note that SCAT is essen- tially providing reference wind information for the CFOSAT small-incidence wave instrument SWIM and as such is well designed for this task.

\section{Conclusions}

In summary, we have presented and assessed a generic simulation framework, which has been adapted to all existing rotating-beam scatterometer types. The representative set of SCAT, WindRad, and SeaWinds is chosen to evaluate the wind retrieval performance of the rotating scatterometers using the $\mathrm{Ku}$ band. The wind retrieval quality strongly de- 

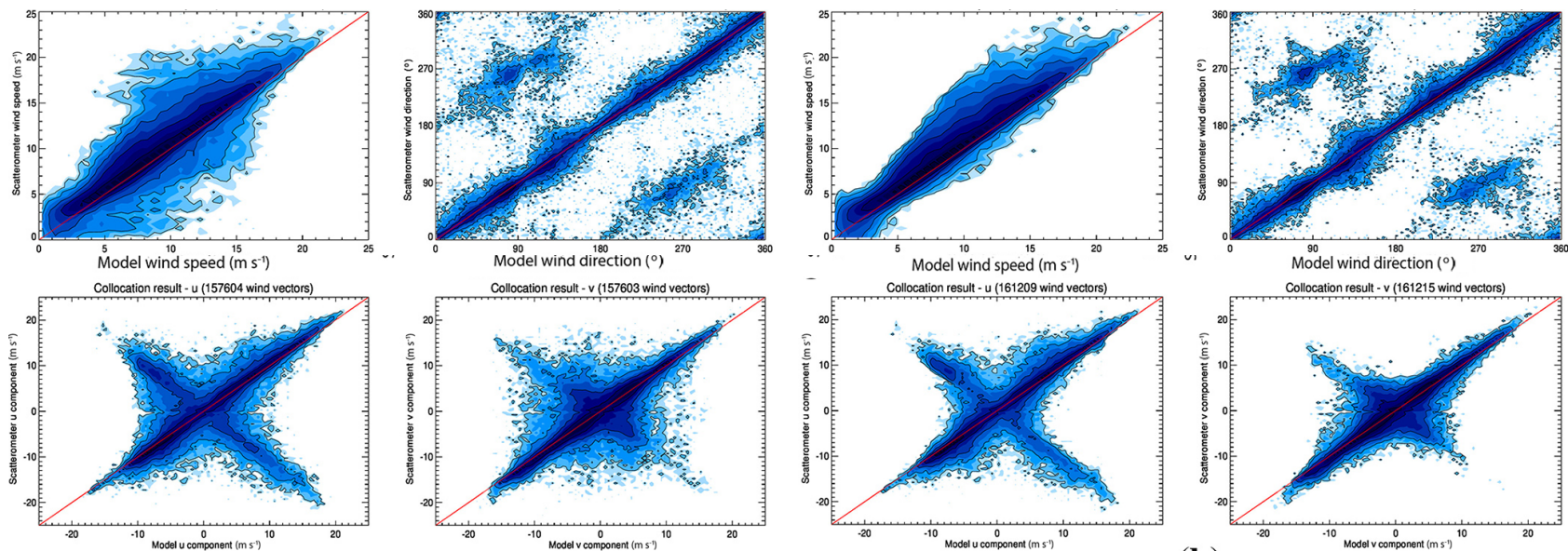

(a)
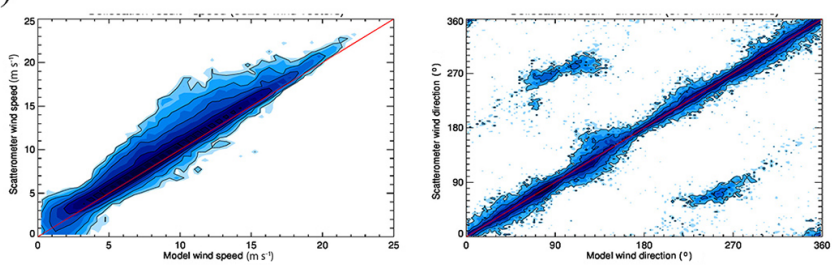

(b)
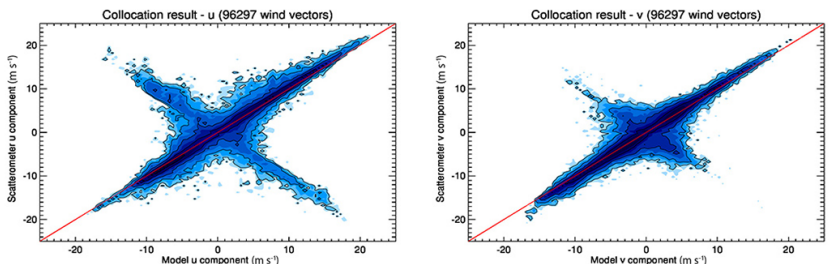

(c)

Figure 24. Contoured histograms of SCAT retrieved first rank wind solution (the views with similar azimuth angles are aggregated into one view) versus input wind field for four orbits. (a) All WVCs within the swath; (b) excluding the WVCs in the outer swath, for which WVC numbers from 8 to 42 are included; (c) excluding the WVCs in the outer swath and nadir swath, for which WVC numbers from 8 to 17 and 26 to 42 are included. From (a) to (c), upper left: wind speed; upper right: wind direction; lower left: $u$ component; lower right: $v$ component. The contour lines are logarithmic.

pends on the location of the WVCs across the swath, and the sweet swath shows the most favorable geometries for wind retrieval. Among the more unfavorable outer and nadir swath regions, SCAT and SeaWinds both perform best in the nadir swath, while for WindRad the outer swath wind retrieval is substantially better than for the other two instruments. On the other hand, WindRad's nadir swath region with lower wind retrieval quality is larger than its outer swath region with degraded quality, while SCAT and SeaWinds have a relatively large outer swath region with degraded quality. The outer swath of SCAT shows both wind speed and wind direction retrieval problems, while for WindRad only the wind speed retrieval is affected. Although rotating fan-beam scatterometers, particularly SCAT, much improve nadir performance with respect to SeaWinds. the nadir swath still shows significant wind direction ambiguity for both SCAT and WindRad.

The increased number of views in the nadir and sweet swath for WindRad does not lead to an improved wind re- trieval, but the wind quality shows a saturation effect and is similar to SCAT. The retrieved wind direction has a tendency to be biased towards the satellite motion direction for all three instruments, which is related to the retrieval procedure. Rain effects are not taken into consideration, so the rain disturbance in the $\mathrm{Ku}$ band and the advantage of the $\mathrm{C}$ band on WindRad cannot be shown here. Future studies may focus on this aspect.

To facilitate good-quality collocations with the CFOSAT SWIM instrument, the SCAT design is clearly focused on an optimal performance close to nadir and employs small incidence angles, combined with a large incidence angle range. This facilitates the availability of additional views near nadir with enhanced azimuth and incidence angle diversity. On the other hand, WindRad's most useful complement is clearly its dual-frequency capability, providing many views in the outer swath, for which excellent performance is obtained according to our simulations. 
This simulation allows us to further investigate the true resolution of the instruments before their launch and also the non-overlap of the views in a WVC, which contributes to the geophysical noise. The WVC size is not the true spatial resolution, and nor is it the true representation of the contributing views, which depend on the spatial response function of each sample, how these are aggregated into a view, and which views contribute to the WVC (Vogelzang et al., 2017; Vogelzang and Stoffelen, 2017). For rotating-beam scatterometers the sampling and hence wind retrieval characteristics vary potentially both by across-track and along-track WVC, which may be further investigated. Such developments may much help users interested in coastal winds.

Our simulation does not consider the rain effect. $\mathrm{Ku}$ band ocean radar returns are affected by rain, and moderate and heavy rain will certainly degrade the wind retrieval. At KNMI, we use the wind retrieval MLE for rain screening of Ku-band systems, much aided by MSS 2DVAR. This successful methodology developed for SeaWinds will also be attempted for CFOSAT. On the other hand, C-band backscatter is much less sensitive to rain and is included in WindRad. This advantage of WindRad should be further investigated, e.g., by using collocated measurements of Ku-band and Cband scatterometers.

The broader user community is looking forward to an increased temporal sampling of the ocean surface with scatterometer winds, including both WindRad and SCAT. These will be useful contributions to the global ocean surface vector winds' virtual constellation.

Data availability. All the data results and specific algorithms created in this study are available from the authors upon request. If you are interested in having access to them, please send an email to li@knmi.nl. The ECMWF data are available at https://www.ecmwf.int/en/forecasts/datasets (last access: 3 July 2019). (registration needed). SeaWinds data are available at https://navigator.eumetsat.int/product/EO:EUM:DAT: QUIKSCAT:REPSW25 (last access: 3 July 2019) (OSI SAF, 2015, https://doi.org/10.15770/EUM_SAF_OSI_0002).

Author contributions. ZL designed the model, collected the data, performed the analysis, and took lead in writing the manuscript. AS contributed to the idea of designing the model and the idea of how to perform the analysis and reviewed the manuscript. AV helped to improve the simulation, contributed his idea of the pencil-beam simulation, and reviewed the manuscript.

Competing interests. The authors declare that they have no conflict of interest.

Acknowledgements. We are grateful to the anonymous reviewers for their constructive and useful comments. We thank Wenming Lin and National Ocean Satellite Application Center China for providing CFOSAT SCAT simulation parameters.

Financial support. This work was supported by the project of "the development and provision of scatterometer wind processing software and wind products for the China France Oceanography SATellite (CFOSAT)" between CNES (Centre National d'etudes Spatiales) and KNMI (Royal Netherlands Meteorological Institute), supported by the EUMETSAT Ocean and Sea Ice Satellite Application Facility (OSI SAF).

Review statement. This paper was edited by Andreas Richter and reviewed by two anonymous referees.

\section{References}

Bajo, M., De Biasio, F., Umgiesser, G., Vignudelli, S., and Zecchetto, S.: Impact of using scatterometer and altimeter data on storm surge forecasting, Ocean Model., 113, 85-94, https://doi.org/10.1016/j.ocemod.2017.03.014, 2017.

Chi, C. Y. and Li, F. K.: A comparative study of several wind estimation algorithms for spaceborne scatterometers, IEEE T. Geosci. Remote, 26, 115-121, https://doi.org/10.1109/36.3011, 1988.

de Vries, J., Stoffelen, A., and Beysens, J.: Ambiguity Removal and Product Monitoring for SeaWinds, de Bilt, the Netherlands, available at: http://www.knmi.nl/scatterometer/ publications/ (last access: 2 July 2019), 2005.

Dou, F., Yin, H., and Gu, S.: Simulation of wind performance in tropical cyclone for China's future dual-frequency wind field radar, Proc. SPIE, 9264, 92641G1-92641G7, 2014.

Dunbar, R. S., Hsiao, S. V., Kim, Y., Pak, K. S., Weiss, B. H., and Zhang, A.: Science Algorithm Specification, Jet Propulsion Laboratory, Pasadena, California, 2001.

Gelsthorpe, R. V., Schied, E., and Wilson, J. J. W.: ASCAT Metop's advanced scatterometer, ESA Bull. Sp. AGENCY, Paris, France, 2000.

Hoffman, R. N. and Leidner, S. M.: An Introduction to the Near Real - Time QuikSCAT Data, Weather Forecast., 20, 476-493, 2005.

Hoots, F. R. and Roehrich, R. L.: Spacetrack Report No. 3-Models for Propagation of NORAD Elements Sets, Department of Defense, Defense Documentation Center, Peterson AFB, CO, 1980.

Jiang, X., Lin, M., Liu, J., Zhang, Y., Xie, X., Peng, H., and Zhou, W.: The HY-2 satellite and its preliminary assessment, Int. J. Digit. Earth, 5, 266-281, https://doi.org/10.1080/17538947.2012.658685, 2012.

JPL: QuikSCAT Science Data Product User's Manual, Jet Propulsion Laboratory, D-12985, Pasadena, USA, 2001.

Li, Z., Verhoef, A., and Stofflen, A.: CWDP L1B simulator and L2A processor Specification and User Manual, KNMI (Royal Netherlands Meteorological Institute), de Bilt, the Netherlands, 2017.

Lin, C.-C., Rommen, B., Wilson, J. J. W., Impagnatiello, F., and Park, P. S.: An analysis of a rotating, range-gated, fanbeam spaceborne scatterometer concept, Geosci. Remote Sensing, 38, 2114-2121, https://doi.org/10.1109/36.868870, 2000a. 
Lin, C. C., Rommen, B., Wilson, J. J. W., Impagnatiello, F., and Park, P. S.: An analysis of a rotating, range-gated, fanbeam spaceborne scatterometer concept, IEEE T. Geosci. Remote, 35, 2114-2121, https://doi.org/10.1109/36.868870, 2000 b.

Lin, C.-C., Stoffelen, A., De Kloe, J., Wismann, V., Bartha, S., and Schulte, H.-R.: Wind retrieval capability of rotating, range-gated, fanbeam spaceborne scatterometer, Proc. SPIE Int. Symp. Remote Sens., pp. 268-285, Crete, Greece, 2002.

Lin, W. and Dong, X.: Design and optimization of a Ku-band rotating, range-gated fanbeam scatterometer, Int. J. Remote Sens., 32, 2151-2171, https://doi.org/10.1080/01431161003674626, 2011.

Liu, W. T., Tang, W., and Xie, X.: wind power distribution over the ocean, Geophys. Res. Lett., 35, 1-6, 2008.

Long, D. G., Yoho, P. K., Yoho, P. K., Long, D. G., and Member, S.: Correlation and covariance of satellite scatterometer measurements, IEEE T. Geosci. Remote, 42, 1179-1187, 2004.

Naderi, F. M., Freilich, M. H., and Long, D. G.: Spaceborne Radar Measurement of Wind Velocity Over the Ocean - An Overview of the NSCAT Scatterometer System, Proc. IEEE, 79, 850-866, https://doi.org/10.1109/5.90163, 1991.

Offiler, D.: A comparison of SEASAT scatterometer-derived winds with JASIN surface winds, Int. J. Remote Sens., 5, 365-378, https://doi.org/10.1080/01431168408948814, 1984.

OSI SAF: SeaWinds L2 $25 \mathrm{~km}$ winds data record release 1 - QuikSCAT, EUMETSAT SAF on Ocean and Sea Ice, https://doi.org/10.15770/EUM_SAF_OSI_0002, 2015.

Pierson, W. J.: Probabilities and statistics for backscatter estimates obtained by a scatterometer, J. Geophys. Res., 94, 9743-9759, https://doi.org/10.1029/JC094iC07p09743, 1989.

Portabella, M.: Wind Field Retrieval from Satellite Radar Systems, University of Barcelona, ISBN 90-6464-499-3, Barcelona, Spain, 2002.

Portabella, M. and Stoffelen, A.: Characterization of residual information for SeaWinds quality control, IEEE T. Geosci. Remote, 4, 2747-2759, https://doi.org/10.1109/TGRS.2002.807750, 2002.
Rivas, M. B., De Kloe, J., and Stoffelen, A.: Study of an Objective Performance Measure for Spaceborne Wind Sensors, de Bilt, the Netherlands, 2009.

Singh, R., Kumar, P., and Pal, P. K.: Assimilation of oceansat-2scatterometer-derived surface winds in the weather research and forecasting model, IEEE T. Geosci. Remote, 50, 1015-1021, https://doi.org/10.1109/TGRS.2011.2164410, 2012.

Stoffelen, A. and Anderson, D.: Ambiguity removal and assimilation of scatterometer data, Q. J. Roy. Meteor. Soc., 123, 491-518, 1997.

Stoffelen, A. and Portabella, M.: On Bayesian Scatterometer Wind Inversion, IEEE T. Geosci. Remote, 44, 1-11, https://doi.org/10.1109/TGRS.2005.862502, 2006.

Ulaby, F. and Long, D. G.: Microwave Radar and Radiometric Remote Sensing, edited by A. Arbor, University of Michigan Press, Michigan, 2013.

Vogelzang, J.: Two-dimensional variational ambiguity removal (2DVAR), de Bilt, the Netherlands, 2013.

Vogelzang, J. and Stoffelen, A.: ASCAT Ultrahigh-Resolution Wind Products on Optimized Grids, IEEE J. Sel. Top. Appl. EARTH Obs. Remote Sens., 10, 2332-2339, 2017.

Vogelzang, J., Verhoef, A., De Vries, J., and Bonekamp, H.: Validation of Two-Dimensional Variational Ambiguity Removal on SeaWinds Scatterometer Data, J. Atmos. Ocean. Tech., 26, 1229-1245, https://doi.org/10.1175/2008JTECHA1232.1, 2009.

Vogelzang, J., Stoffelen, A., Lindsley, R. D., Verhoef, A., and Verspeek, J.: The ASCAT 6.25-km wind product, IEEE J. Sel. Top. Appl. EARTH Obs. Remote Sens., 10, 2321-2331, 2017.

Wang, Z., Stoffelen, A., Zhang, B., He, Y., Lin, W., and Li, X.: Inconsistencies in scatterometer wind products based on ASCAT and OSCAT- 2 collocations, Remote Sens. Environ., 225, 207216, https://doi.org/10.1016/j.rse.2019.03.005, 2019. 